OPEN ACCESS

Edited by:

Marcin Filip Osuchowski, Ludwig Boltzmann Institute for

Experimental and Clinical

Traumatology, Austria

Reviewed by:

Matthijs Kox,

Radboud University Nijmegen Medical

Centre, Netherlands

Matthias Clauss,

Indiana University Bloomington,

United States

*Correspondence:

David Alexander Christian Messerer david.messerer@uni-ulm.de

Specialty section:

This article was submitted to Inflammation,

a section of the journal

Frontiers in Immunology

Received: 16 December 2020

Accepted: 15 February 2021

Published: 16 March 2021

Citation:

Hug S, Bernhard S, Stratmann AEP, Erber M, Wohlgemuth L, Knapp CL, Bauer JM, Vidoni L, Fauler $M$

Föhr KJ, Radermacher P, Hoffmann A,

Huber-Lang $M$ and Messerer DAC

(2021) Activation of Neutrophil

Granulocytes by Platelet-Activating

Factor Is Impaired During Experimental

Sepsis. Front. Immunol. 12:642867.

doi: 10.3389/fimmu.2021.642867

\title{
Activation of Neutrophil Granulocytes by Platelet-Activating Factor Is Impaired During Experimental Sepsis
}

\begin{abstract}
Stefan Hug ${ }^{1}$, Stefan Bernhard ${ }^{1}$, Alexander Elias Paul Stratmann ${ }^{1}$, Maike Erber ${ }^{1}$, Lisa Wohlgemuth ${ }^{1}$, Christiane Leonie Knapp ${ }^{1}$, Jonas Martin Bauer ${ }^{1}$, Laura Vidoni ${ }^{1}$, Michael Fauler ${ }^{2}$, Karl Josef Föhr ${ }^{3}$, Peter Radermacher ${ }^{4}$, Andrea Hoffmann ${ }^{4}$, Markus Huber-Lang ${ }^{1}$ and David Alexander Christian Messerer ${ }^{1,3,4 *}$
\end{abstract}

${ }^{1}$ Institute of Clinical and Experimental Trauma Immunology, University Hospital of UIm, UIm, Germany, ${ }^{2}$ Institute of General Physiology, University of Ulm, Ulm, Germany, ${ }^{3}$ Department of Anesthesiology and Intensive Care Medicine, University Hospital of Ulm, Ulm, Germany, ${ }^{4}$ Institute of Anesthesiological Pathophysiology and Process Development, University Hospital of UIm, UIm, Germany

Platelet-activating factor (PAF) is an important mediator of the systemic inflammatory response. In the case of sepsis, proper activation and function of neutrophils as the first line of cellular defense are based on a well-balanced physiological response. However, little is known about the role of PAF in cellular changes of neutrophils during sepsis. Therefore, this study investigates the reaction patterns of neutrophils induced by PAF with a focus on membrane potential (MP), intracellular $\mathrm{pH}$, and cellular swelling under physiological and pathophysiological conditions and hypothesizes that the PAF-mediated response of granulocytes is altered during sepsis. The cellular response of granulocytes including MP, intracellular $\mathrm{pH}$, cellular swelling, and other activation markers were analyzed by multiparametric flow cytometry. In addition, the chemotactic activity and the formation of platelet-neutrophil complexes after exposure to PAF were investigated. The changes of the (electro-)physiological response features were translationally verified in a human ex vivo whole blood model of endotoxemia as well as during polymicrobial porcine sepsis. In neutrophils from healthy human donors, PAF elicited a rapid depolarization, an intracellular alkalization, and an increase in cell size in a time- and dose-dependent manner. Mechanistically, the alkalization was dependent on sodium-proton exchanger 1 (NHE1) activity, while the change in cellular shape was sodium flux- but only partially NHE1-dependent. In a pathophysiological altered environment, the PAF-induced response of neutrophils was modulated. Acidifying the extracellular $\mathrm{pH}$ in vitro enhanced PAF-mediated depolarization, whereas the increases in cell size and intracellular pH were largely unaffected. Ex vivo exposure of human whole blood to lipopolysaccharide diminished the PAF-induced intracellular alkalization and the change in neutrophil size. During experimental porcine sepsis, depolarization of the MP was significantly impaired. Additionally, there was a trend for increased cellular swelling, whereas intracellular alkalization remained stable. Overall, an impaired 
(electro-)physiological response of neutrophils to PAF stimulation represents a cellular hallmark of those cells challenged during systemic inflammation. Furthermore, this altered response may be indicative of and causative for the development of neutrophil dysfunction during sepsis.

Keywords: platelet-activating factor, neutrophil granulocytes, intracellular $\mathrm{pH}$, sepsis, membrane potential, flow cytometry

\section{INTRODUCTION}

Platelet-activating factor (PAF) is a phospholipid mediator with well-described proinflammatory properties, among others, by activating thrombocytes and leukocytes $(1,2)$. The importance of PAF has been investigated in many other diseases, in particular in chronic inflammation including coronary artery disease, asthma, and rheumatoid arthritis, as well as in acute inflammation such as trauma and sepsis (1-4).

Sepsis is defined as life-threatening organ dysfunction caused by a dysregulated host response to infection (5). Upon overwhelming stimulation, the immune system becomes excessively activated, resulting in a dysfunctional immune response, which contributes to multi-organ dysfunction syndrome, and ultimately, lethality $(5,6)$. In this context, previous studies in cecal ligation and puncture-induced rodent sepsis reported some beneficial effects by inhibiting PAF activity (7). However, despite initial encouraging results in a phase II study $(8,9)$, PAF degradation (10) or administration of PAF receptor antagonists (11) failed to reduce lethality in patients with severe sepsis.

Neutrophils are the vanguard of innate cellular immunity being crucially involved in the clearance of pathogens. The activity of neutrophils is driven by many proinflammatory mediators including anaphylatoxins such as PAF and the complement cleavage product $\mathrm{C} 5 \mathrm{a}$, interleukins, microbeassociated molecular patterns (MAMPs, e.g., fMLF), and many other factors, activate neutrophils $(6,12-15)$. On a cellular level, neutrophils respond with membrane potential (MP) depolarization likely generated by NADPH oxidase (NOX) activity $(16,17)$. Additionally, the intracellular $\mathrm{pH}\left(\mathrm{pH}_{\mathrm{i}}\right)$ of neutrophils increases transiently $(15,18)$, regulating important cellular functions, for example, interference of apoptosis (19, 20), and modulation of chemotactic activity (21-23). Moreover, neutrophil activation by chemoattractants results in changes in the cellular shape and chemotaxis $(14,24)$, the generation of reactive oxygen species (ROS) $(25,26)$, and the expression of surface activation markers. For the last, an upregulation of integrin alpha M (CD11b) was found to facilitate leukocyte adhesion and L-selectin (CD62L) shedding, which both are considered to be hallmarks of neutrophil diapedesis into peripheral tissues (27-29).

The PAF-induced response in various cell types, including neutrophils, was investigated previously. For example, PAF induced a depolarization in rat endothelial cells (30), guinea pig neurons (31), and human neutrophils (32). Moreover, PAF mediated a small increase in $\mathrm{pH}_{\mathrm{i}}$ in bovine neutrophils $(33,34)$, while in human neutrophils an initial acidification and consecutive small rebound alkalization was described (35). During systemic inflammation, cellular parameters of neutrophils have been reported to be altered. For example, in murine sepsis, an increase in neutrophil cell size (14) and $\mathrm{pH}_{\mathrm{i}}$ were reported, with the latter verified in patients with sepsis (15). Both alterations have been confirmed in an ex vivo model of lipopolysaccharide (LPS)-induced inflammation (36). In this context, it is tempting to speculate that a shift in baseline levels of neutrophil parameters during systemic inflammation affects the response under additional stimulation by inflammatory mediators such as PAF, however, this remains to be further elucidated.

Therefore, in this study, we investigated the cellular response induced by PAF in neutrophils in a multi-step approach: Firstly, under physiological conditions and, secondly mechanistically by identifying the sodium-proton antiport as an important ion transport protein. Finally, we translationally analyzed the response elicited by PAF during inflammation in the setting of in vitro acidosis, in an ex vivo whole blood model of LPS-driven inflammation, and in a porcine model of polymicrobial sepsis.

\section{MATERIALS AND METHODS}

All chemicals were purchased from Merck (Darmstadt, Germany), when not indicated otherwise.

\section{Isolation of Neutrophils}

The investigations were approved by the Local Independent Ethics Committee of the University of Ulm (number 459/18; 94/14). After obtaining informed written consent from healthy human volunteers, blood was drawn into syringes containing 3.2\% trisodium citrate (Sarstedt, Nürnbrecht, Germany). Neutrophils were isolated by Ficoll-Paque (GE Healthcare, Uppsala, Sweden) density gradient centrifugation and subsequent dextran sedimentation followed by hypotonic lysis of remaining erythrocytes, as described previously (1416). Polymorphonuclear granulocytes (mainly consisting of neutrophils) were adjusted to a concentration of 2 $\times 10^{6}$ cells/ml using Hank's balanced salt solution with calcium and magnesium (HBSS, Thermo Fisher, Darmstadt, Germany), the $\mathrm{pH}$ of which was adjusted to 7.3 , when not indicated otherwise.

\section{Measurement of Neutrophil Membrane Potential, Intracellular pH, and Cell Size}

Isolated neutrophils were incubated in a light-protected water bath at $37^{\circ} \mathrm{C}$ with the fluorescent dyes bis(1,3-dibutylbarbituric 
acid) trimethine oxonol $\left(\mathrm{DiBAC}_{4}(3)\right), 50 \mathrm{nM}$, or 5-(and6)-carboxy-SNARF-1 (SNARF), $1 \mu \mathrm{M}$ (Thermo Fisher) for $20 \mathrm{~min}$ or with dihydrorhodamine 123 (D123) (Santa Cruz Biotechnology, Heidelberg, Germany), $1.8 \mu \mathrm{M}$, for $30 \mathrm{~min}$ to determine MP (16), $\mathrm{pH}_{\mathrm{i}}$, and $\mathrm{ROS}$ generation [what is measured by $\mathrm{D} 123$ is the byproduct $\mathrm{H}_{2} \mathrm{O}_{2}$ which is itself derived from $\mathrm{O}_{2}^{\bullet-}$, a product generated by NOX activity (37)], respectively. To determine porcine neutrophil $\mathrm{pH}_{\mathrm{i}}$, the cells were instead incubated with $2^{\prime}, 7^{\prime}$-bis-(2-carboxyethyl)5-(and-6)-carboxyfluorescein, acetoxymethyl ester (BCECF, Abcam, Cambridge, United Kingdom), $25 \mathrm{nM}$, for $30 \mathrm{~min}$, because exposure of porcine neutrophils to SNARF resulted in changes in forward scatter area (FSC-A), which was interpreted as possible cellular activation (data not shown). Following incubation, neutrophils were centrifuged for $5 \mathrm{~min}$ ( $340 \mathrm{~g}$ ) and resuspended in Roswell Park Memorial Institute medium (RPMI) with magnesium and calcium with a $\mathrm{pH}$ adjusted to 7.3. $\operatorname{DiBAC}_{4}(3)$ was again added. After a resting period of $10 \mathrm{~min}$ in a light-protected water bath at $37^{\circ} \mathrm{C}$, neutrophils were stimulated with $1 \mu \mathrm{M}$ PAF or $100 \mathrm{ng} / \mathrm{ml}$ complement factor 5a (C5a, Complement Technology, Tyler, Texas, USA), when not indicated otherwise. Cells were analyzed using a Canto II flow cytometer (BD Biosciences, Heidelberg, Germany). Neutrophils were identified by FSC-A and sideward scatter area. Non-fluorescent reference microspheres (10, 15,

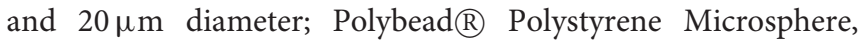
Polysciences, Hirschberg, Germany) were used to quantify the shape changes assessed by the FSC-A (14). Differences in absolute FSC-A values between experiments are explained by recalibration of the flow cytometer between different experimental series. The fluorescence of $\operatorname{DiBAC}_{4}(3)$ were converted in changes of the MP as described previously (16) with a small modification: RPMI with varying extracellular concentrations of sodium and potassium were used to calculate the amount of change in $\mathrm{DiBAC}_{4}(3)$ fluorescence per $\mathrm{mV}$.

Near-real time kinetics were measured by acquiring neutrophils for $10 \mathrm{~min}$ continuously embedded in a heating unit (TC-1234A Temperature Controller, Warner Instruments LLC, Holliston, Massachusetts, USA), ensuring a steady temperature level of $37^{\circ} \mathrm{C}$. Analysis was performed by a specifically designed algorithm using the statistic language $\mathrm{R}(\mathrm{R}$ Core Team, Vienna, Austria).

\section{Cell Surface Markers}

Isolated neutrophils were incubated in a light-protected water bath at $37^{\circ} \mathrm{C}$. Following PAF stimulation as indicated above (normally $1 \mu \mathrm{M}$ ) for $10 \mathrm{~min}$, neutrophils were stained with $0.1 \mu \mathrm{g} / \mathrm{ml}$ APC anti-mouse/human CD11b antibody (\#101212, Biolegend, San Diego, USA) and $0.5 \mu \mathrm{g} / \mathrm{ml}$ PE anti-human CD62L antibody (\#304806, Biolegend) for $5 \mathrm{~min}$ at room temperature. Cells were fixed using FACS Lysing Solution (BD, Heidelberg, Germany). Proper isotype controls were used (CD11b: APC Rat

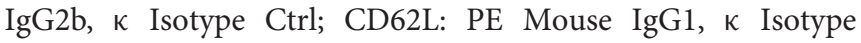
Ctrl; Biolegend).

\section{In vitro Pharmacological Modification}

PAF-induced effects on neutrophils were analyzed in the presence of the subsequently listed pharmacological modulators (their proposed targets are given in brackets): Amiloride $[200 \mu \mathrm{M}$, $10 \mathrm{~min}, \mathrm{Na}^{+}$-channels (15)], BIX [ $5 \mu \mathrm{M}, 30 \mathrm{~min}$, sodium-proton exchanger 1 (NHE1) (38); Tocris, Wiesbaden, Germany], 5Nitro-2-(3-phenylpropylamino)benzoic acid [NPPB, $100 \mu \mathrm{M}$, $10 \mathrm{~min}, \mathrm{Cl}^{-}$channels (39)], and ebselen [10 $\mathrm{nM}, 30 \mathrm{~min}$, glutathione peroxidase and peroxiredoxin enzyme mimetic and NOX2 inhibitor $(40,41)$; Tocris]. Following pre-incubation, samples were divided to obtain paired results and treated as control or stimulated with PAF.

\section{Extracellular Alkalosis and Acidification in vitro}

Following the described staining and centrifugation, neutrophils were resuspended in RPMI adjusted to a $\mathrm{pH}$ of $6.6,7.0,7.4$, or 7.8 to simulate extracellular alkalosis or acidification. Neutrophils were incubated for $10 \mathrm{~min}$ at $37^{\circ} \mathrm{C}$ and subsequently stimulated with PAF.

\section{Coulter Counter Measurements}

Isolated neutrophils were stimulated for $10 \mathrm{~min}$, diluted 1:500 with RPMI adjusted to a $\mathrm{pH} 7.3$ and measured by a cell counter working through electronic current exclusion (Cell Counter CASY, OLS OMNI Life Science, Bremen, Germany).

\section{Chemotaxis}

Neutrophil chemotactic activity was assessed using a Neuro Probe A96 chemotaxis chamber (Neuro Probe, Gaithersburg, Maryland, USA). Isolated neutrophils at $5 \times 10^{6}$ cells $/ \mathrm{ml}$ in HBSS $+0.1 \%$ bovine serum albumin (BSA) were stained with the fluorescent dye BCECF $(1.6 \mu \mathrm{g} / \mathrm{ml})$ for $30 \mathrm{~min}$ at $37^{\circ} \mathrm{C}$, subsequently centrifuged for $5 \mathrm{~min}(340 \mathrm{~g})$, and resuspended in HBSS $+0.1 \%$ BSA. A total of $33 \mu \mathrm{l}$ chemoattractant PAF (final concentration $1 \mu \mathrm{M}$ ) was added into the wells of the lower plate. Thereafter, a silicone gasket and a framed filter with $3 \mu \mathrm{m}$ pores were placed upon the lower wells. On top of it, the upper plate was attached, and the dyed neutrophils were pipetted into the corresponding wells. During incubation for $30 \mathrm{~min}$ at $37^{\circ} \mathrm{C}$, neutrophils migrated from the upper wells toward the lower wells containing PAF, but became adherent to the filter, resulting in increased fluorescence. The fluorescence of the cells in the filter was measured at a wavelength of 485/538 nm using a Fluoroskan Ascent (Thermo Scientific, Rockford, Illinois, USA) with the Ascent Software Version 2.6.

\section{Quantification of Platelet-Neutrophil Complex Formation}

Platelet-neutrophil complex (PNC) formation, defined as a neutrophil with at least one platelet in direct proximity, was assessed as described previously by light microscopy and flow cytometry $(36,42)$. For blood smears, whole blood was diluted 1:1 with phosphate-buffered saline containing calcium and magnesium (PBS) and incubated for $15 \mathrm{~min}$ at $37^{\circ} \mathrm{C}$ with or without $1 \mu \mathrm{M}$ PAF on a spinning wheel (Snijders Labs, Tilburg, Netherlands) at $3 \mathrm{rpm}$. Blood smears were created 
and stained with Hemacolor@ Rapid staining (Merck). In each sample, 50 neutrophils were counted by two independent and blinded individuals. For flow cytometry analysis, whole blood was diluted 1:5 with PBS. Following 15 min of incubation with or without $1 \mu \mathrm{M}$ PAF, the sample was stained with anti-CD41 APC $(125 \mathrm{ng} / \mathrm{ml}, \# 303710$, Biolegend) and anti-CD61 PerCP (250 ng/ml, \# 336412, Biolegend; both monoclonal mouse antihuman antibodies) for $15 \mathrm{~min}$ at room temperature followed by 30 min incubation with $1 \mathrm{ml}$ of $1 \mathrm{X}$ BD FACS Lysing solution (BD Biosciences, San Jose, California, USA). Samples were centrifuged for $5 \mathrm{~min}$ at $340 \mathrm{~g}$ and resuspended in $100 \mu \mathrm{l}$ PBS $+0.1 \% \mathrm{BSA}$ and stored at $4^{\circ} \mathrm{C}$ in the dark until further analysis (normally within $1 \mathrm{~h}$ ).

\section{Ex vivo Human Whole Blood Model of Endotoxemia}

An animal-free human whole blood model of endotoxemia was used to investigate the effect of LPS exposure on the PAF-induced response of neutrophils, which was described previously in detail (36). In brief, $0.5 \mathrm{IU} / \mathrm{ml}$ heparin (B. Braun Melsungen AG, Melsungen, Germany) and $100 \mathrm{ng} / \mathrm{ml}$ LPS (\#L2630, Merck) or PBS (control) were added to $9 \mathrm{ml}$ blood, which was transferred into a Cortiva BioActive Surface (Medtronic, Meerbusch, Germany) coated tubing system using a coated connector (Medtronic) to interlink both ends. Following $1 \mathrm{~h}$ of rotation $(3 \mathrm{rpm})$ on a spinning wheel (Snijders Labs) at $37^{\circ} \mathrm{C}$, the blood was transferred to citrate anti-coagulated monovettes (Sarstedt). Neutrophil activation markers were analyzed directly in whole blood as described previously (36) with or without exposure to $\operatorname{PAF}\left(1 \mu \mathrm{M}, 15 \mathrm{~min}, 37^{\circ} \mathrm{C}\right)$. The remaining whole blood was processed to isolate and to analyze neutrophils as described above.

\section{Porcine Polymicrobial Sepsis}

The Federal authorities for animal research (\#1362, Tuebingen, Germany) as well as the Animal Care Committee of the University of Ulm approved the experiments. The welldescribed porcine sepsis model was performed in adherence with guidelines on the Use of Laboratory Animals of the National Institutes of Health with anesthesia and surgical instrumentation as described previously (43-45). In brief, nine BretoncellesMeishan-Willebrand pigs (5 male-castrated, 4 female, mean weight $65.6 \mathrm{~kg} \pm 8.6$ ) were subjected to polymicrobial sepsis induced by inoculation of autologous feces into the abdominal cavity, followed by intensive care therapy for $60 \mathrm{~h}$ after the sepsis initiation. Blood was drawn before inoculation and when the mean arterial pressure was reduced by $>10 \%$, indicating cardiocirculatory shock and triggering the beginning of resuscitation. To reduce animal numbers, the analyzed pigs are a subgroup of another currently unpublished trial comparing standard intensive care therapy with or without a pharmacological intervention targeting the calcitonin generelated peptide receptor. Because intervention started after the fulfillment of the sepsis criteria listed above, animals were included irrespective of their group allocation.

\section{Data Presentation and Statistical Analysis}

Results are presented as mean \pm standard deviation (SD), when not indicated otherwise. In all experiments, a minimum of 3,000 neutrophils were measured. All data were considered to be paired and non-parametric. Statistical significance is indicated by $*, * *$, and $* * *$, with significance levels of $p<0.05,<0.01$, and $<0.001$, respectively. Statistical analysis was performed using GraphPad Prism 9 (GraphPad Software Inc., San Diego, California, USA) and Microsoft Excel (Version 16.42, Microsoft Corporation, Redmond, Washington, USA).

\section{RESULTS}

\section{PAF Induced Changes in Neutrophil Physiology in a Dose- and Time-Dependent Manner}

Neutrophils responded to PAF stimulation with a rapid increase in cell size, peaking after $20 \mathrm{~min}$ with a relative increase of $73 \pm 19 \%$ (Figures 1A,B). A near-real time measurement demonstrated that most of the size change occurred within in the first minutes (Figure 1A). The increase in the FSC-A induced by PAF was similar to the stimulation with C5a (Figure 1B). Using reference microspheres, the calculated diameters of unstimulated cells were $16.9 \pm 1.1 \mu \mathrm{m}$, and $26.1 \pm 0.6 \mu \mathrm{m}$ for PAF-stimulated cells (after $10 \mathrm{~min}, p=0.06, n=5$, representative measurement in Figure 1C). The change in neutrophil size was verified by Coulter counter measurement. Following $10 \mathrm{~min}$ of incubation with PAF, neutrophils exhibited an increase of $3.6 \pm 1.7 \%$ in diameter and $10.5 \pm 6.4 \%$ in volume in comparison with unstimulated neutrophils (Figure 1D).

Next, the response elicited by PAF on the neutrophil MP and $\mathrm{pH}_{\mathrm{i}}$ was investigated. PAF rapidly induced a depolarization peaking after $1 \mathrm{~min}$ (Figure 2A) and an intracellular alkalization attaining a maximum of $+0.45 \pm 0.07$ after 5 min (Figure 2B). In addition, PAF induced an increase in ROS production $(+26$ $\pm 11 \%$ after $10 \mathrm{~min}, p<0.001$ Wilcoxon signed-rank test, $n=$ 17 , data not shown). Depolarization and intracellular alkalization revealed different kinetics (Figures 2A-C). The PAF-induced response was comparable to $\mathrm{C} 5 \mathrm{a}$-stimulation for cell size and $\mathrm{pH}_{\mathrm{i}}$ but was more intensive for the MP ( 1 min: PAF $+12 \pm 4 \mathrm{mV}$, C5a: $7 \pm 3 \mathrm{mV}$, Figures 2A,B). All PAF-induced effects showed a clear concentration-response relationship (Supplement 1). The $\mathrm{EC}_{50^{-}}$ values are presented in Figure 2D and ranged between 14 and $128 \mathrm{nM}$.

In accordance with previous findings, neutrophils responded to PAF stimulation with an increased chemotactic activity (15.8 \pm 9.7 fold increase after $30 \mathrm{~min}, p<0.05$ Wilcoxon signed-rank test, $n=6)$, CD11b upregulation $(+63.3 \pm 41.9 \%$ after $10 \mathrm{~min}, p$ $<0.01$ Wilcoxon signed-rank test, $n=8)$, and CD62L shedding $(-87 \pm 10 \%$ surface expression after $10 \mathrm{~min}, p<0.01$ Wilcoxon signed-rank test, $n=8$ ) (Supplements 1, 2). In addition, PAF induced formation of PNCs (Figure 3). For all these effects, there was no significant difference when comparing neutrophils from male and female donors (Supplement 2). 


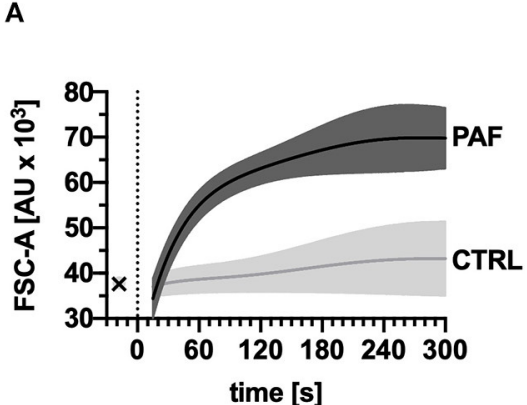

C

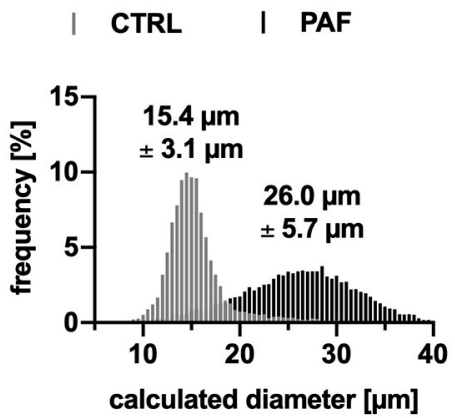

B

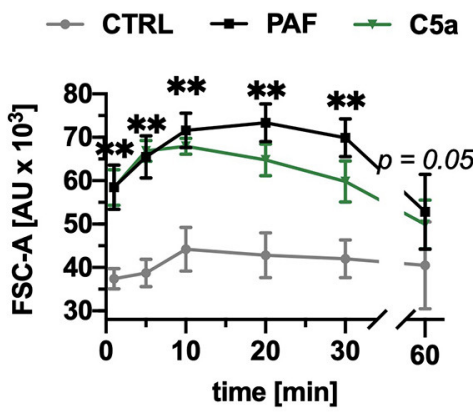

D

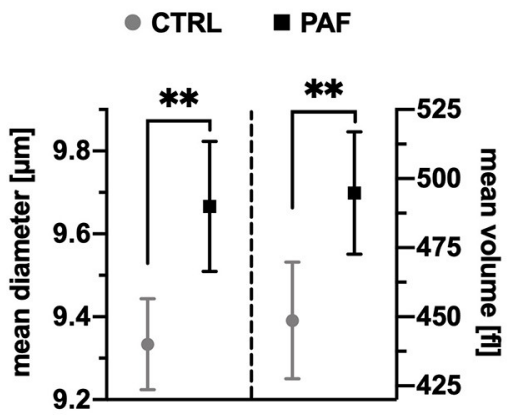

FIGURE 1 | PAF elicited a rapid increase in size of human neutrophils. (A) FSC-A (forward scatter area) of neutrophils stimulated by PAF (1 $\mu$ M, black) or PBS (CTRL, gray), measured by continuous acquisition by flow cytometry for $5 \mathrm{~min}$, $\mathrm{x}$ indicating baseline measurement, $n=5$. (B) FSC-A of neutrophils stimulated with PAF or PBS for $60 \mathrm{~min}, n=15$. For comparison, neutrophils exposed to C5a (green) are shown. (C) Calculated diameter of neutrophils using counting beads (10, 15, and $20 \mu \mathrm{m}$ ) from one representative donor with or without PAF exposure. (D) Mean diameter and volume of neutrophils stimulated by PAF or PBS measured by Coulter counter, $n=8$. Data are mean \pm SD. ${ }^{*} p<0.01$, Wilcoxon matched-pairs signed rank test comparing PAF-stimulated neutrophils with unstimulated control cells.

\section{Ion Transport Proteins and NOX2 Modulated the PAF-mediated Neutrophil Response}

Ion fluxes in stimulated neutrophils are crucially involved in cellular activity. Unspecific inhibition of sodium or chloride flux inhibited most cellular changes induced by PAF (Figures $4 \mathrm{~A}, \mathrm{C}$ ), however, in parallel also partially altering unstimulated neutrophils (Supplement 3).

A more detailed analysis revealed that PAF-induced intracellular alkalization was completely inhibited by targeting NHE1 activity with BIX $(+0.30 \pm 0.07$ vs. $-0.02 \pm 0.04$, $p<0.01)$. Cellular swelling and the ROS generation were also reduced, but to a lesser extent, by targeting NHE1 (Figure 4B). PAF-induced depolarization and CD62L shedding displayed no difference during selective NHE1 inhibition. PAF-induced CD11b expression increased during selective NHE1 inhibition, whereas it was fully inhibited by amiloride. However, during incubation with the NHE1 inhibitor BIX, neutrophils expressed less CD11b than cells without an inhibitor (Supplement 3).

Mimicking glutathione peroxidase activity and inhibiting NOX2 with ebselen significantly lowered PAF-induced generation of intracellular alkalization, ROS generation and CD62L shedding (Figure 4D).

\section{Acidosis Significantly Enhanced PAF-mediated Depolarization}

The first step to investigate the above-mentioned PAF-elicited effects under pathologic conditions was to expose neutrophils to buffers of various extracellular $\mathrm{pH}\left(\mathrm{pH}_{\mathrm{e}}\right)$. The $\mathrm{pH}_{\mathrm{e}}$ had no influence on the PAF-induced increase in the FSC-A (Figure 5A). Depolarization after PAF stimulation was significantly enhanced under acid extracellular conditions $\left(\mathrm{pH}_{\mathrm{e}} 6.6=+23.6 \pm\right.$ $7.5 \mathrm{mV}$ vs. $\mathrm{pH}_{\mathrm{e}} 7.4=+10.7 \pm 3.1 \mathrm{mV}, p<0.01$ KruskalWallis test and Dunn's multiple comparison test, $n=6$, Figure 5B). Regarding the $\mathrm{pH}_{\mathrm{i}}$, neutrophils responded with an equal intracellular alkalization when stimulated with PAF under different extracellular conditions. In addition, the $\mathrm{pH}_{\mathrm{i}}$ of neutrophils shifted with the $\mathrm{pH}_{\mathrm{e}}$, therefore with rising $\mathrm{pH}_{\mathrm{e}}$, the $\mathrm{pH}_{\mathrm{i}}$ increased in parallel (Figure 5C).

\section{Endotoxemia Modulated the PAF-induced Response of Neutrophils}

To translate the findings to a more clinically relevant setting, an ex vivo model of human endotoxemia was used analyzing the modulation of the PAF-induced response in systemic inflammation. As previously reported (36), sole contact with the tubing system of the model did not promote neutrophil activation (data not shown). However, the exposure to LPS 


\section{A}

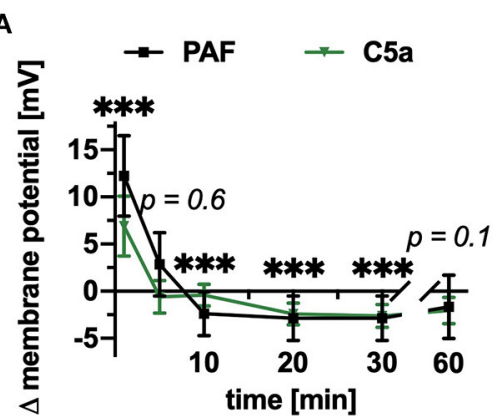

C

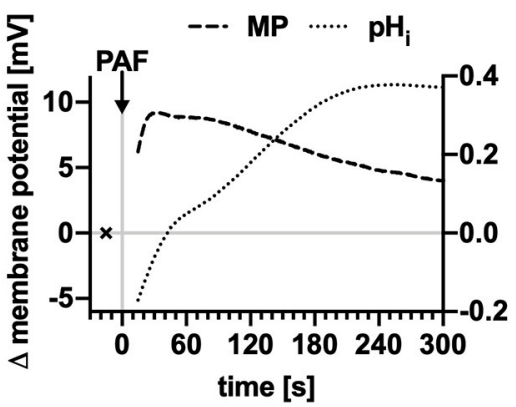

B

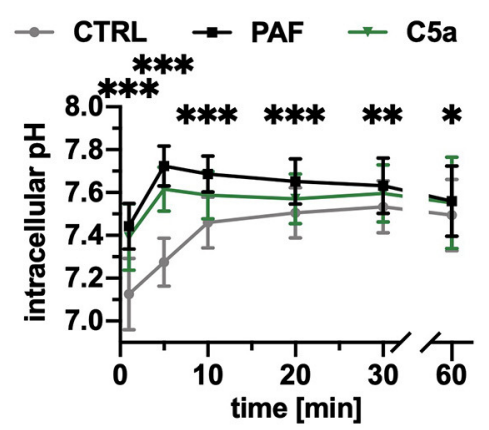

D
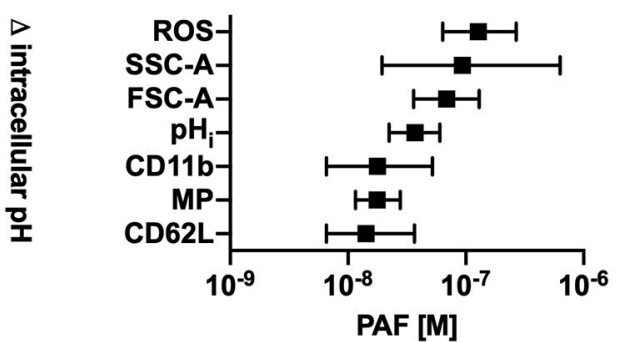

FIGURE 2 | PAF depolarized the membrane potential and increased the intracellular $\mathrm{pH}$ of human neutrophils within seconds. (A) Changes in membrane potential of neutrophils stimulated with PAF $(1 \mu \mathrm{M})$ or C5a (green, $10 \mathrm{nM}), n=15$, unstimulated cells $=0 \mathrm{mV}$. (B) Intracellular pH of neutrophils upon stimulation with PAF, C5a, or PBS (CTRL), $n=15$. (C) Changes in membrane potential and intracellular $\mathrm{pH}$ of neutrophils exposed to PAF measured by continuous acquisition on flow cytometry. $\mathrm{x}$ represents the baseline measurement prior to stimulation. Depicted is one representative donor out of five independent experiments. (D) PAF-induced effects on neutrophils were concentration-dependent (ROS, reactive oxygen species; SSC-A, side scatter area; FSC-A, forward scatter area; $\mathrm{pH}$, intracellular pH; CD11b, integrin alpha M; MP, membrane potential; CD62L, L-selectin) and respective $\mathrm{EC}_{50} \pm$ interquartile range were calculated $(n=5-10)$. (A,B) data are mean \pm SD. ${ }^{*} p<$ $0.05,{ }^{\star \star} p<0.01,{ }^{\star \star \star} p<0.001$, Wilcoxon signed-rank test (A) and Wilcoxon matched-pairs signed rank test (B) comparing PAF-stimulated neutrophils with unstimulated control cells.

$(100 \mathrm{ng} / \mathrm{ml})$ resulted in an activated neutrophil phenotype as reflected by of the upregulation of the surface expression of CD11b and downregulation of CD62L. These alterations in baseline expression of these activation markers also modulated the response generated by additional in vitro stimulation with PAF (increase in CD62L downregulation, reduction in CD11b upregulation, Figures 6A,B).

LPS exposure resulted in increased cellular size, $\mathrm{pH}_{\mathrm{i}}$, and generation of ROS, but not depolarization in neutrophils without further PAF stimulation. The PAF-induced increase in cellular size was significantly reduced after exposure to LPS (CTRL-PAF $+64 \pm 10 \%$ vs. LPS-PAF $+8 \pm 3 \%, p<0.05$, Figure 6C). There was no significant difference in PAF-mediated depolarization after exposure to LPS (Figure 6D). Transient intracellular alkalization elicited by PAF was significantly reduced in neutrophils after endotoxemia (CTRL-PAF $+0.33 \pm 0.05$ vs. LPS-PAF $+0.02 \pm 0.05, p<0.05$, Figure 6E). The PAF-induced elevation in ROS generation was reduced after LPS exposure (CTRL-PAF $+23 \pm 12 \%$ vs. LPS-PAF $-9 \pm 15 \%$, Figure 6 F).

\section{Sepsis Partially Impaired PAF-induced Neutrophil Activation}

To validate the in vitro and ex vivo results, neutrophils isolated from a porcine polymicrobial sepsis model were investigated before and during sepsis. Clinical parameters and electrolytes are summarized in Table 1. The baseline FSC-A and $\mathrm{pH}_{\mathrm{i}}$ of neutrophils without PAF stimulation remained stable before and during sepsis (data not shown). The PAF-induced change in cellular shape displayed a trend for an increase during sepsis $(+0 \pm 7 \%$ before vs. $+12 \pm 10 \%$ during sepsis, $p=$ 0.08 , Figure 7A). PAF-mediated depolarization was significantly diminished during sepsis $(+17.1 \pm 5.6 \mathrm{mV}$ before vs. +2.6 $\pm 2.2 \mathrm{mV}$ during sepsis, $p<0.05$, Figure 7B). There was no difference between neutrophils before and during sepsis regarding the PAF-induced intracellular alkalization (Figure 7C).

\section{DISCUSSION}

\section{PAF-induced Depolarization, Alkalization, and Cellular Swelling Under Physiological Conditions}

The inflammatory mediator PAF induced a rapid sequence of cellular reactions in neutrophils in a concentration- and time-dependent manner as summarized in Figure 8. The initial depolarization within seconds can likely be explained by the activation of the NOX activity resulting in excessive electron extrusion (17). This is corroborated by increased ROS generation 


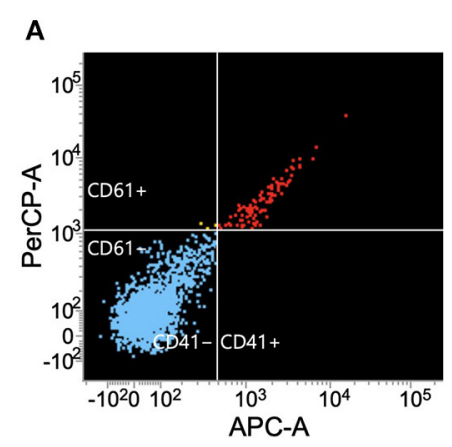

B

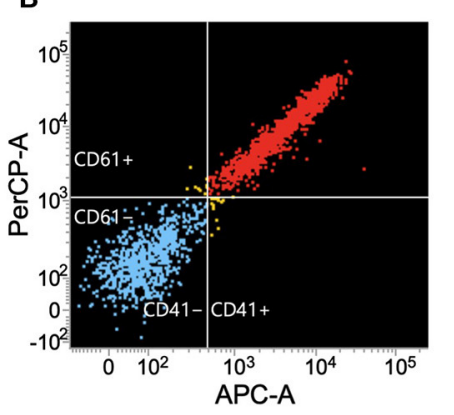

C

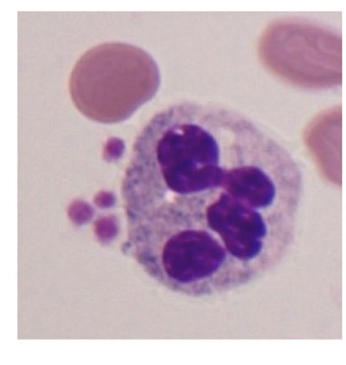

D

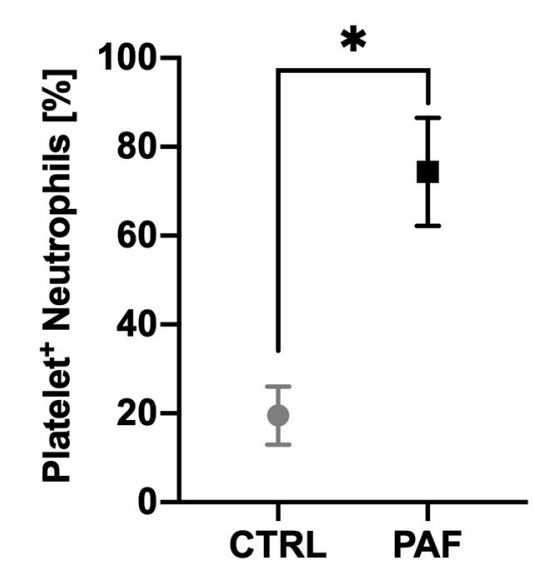

E blood smear PerCP-labeled anti-CD61 antibodies. Shown is one representative donor for blood stimulated with PBS (CTRL, A) or PAF $1 \mu M$ (B). Blue indicates CD41- and CD61-negative cells, yellow indicates either CD41- or CD61-positive neutrophils, red refers to neutrophils positive for CD41 and CD61. (C) Light microscopy of an exemplary PNC. (D) Quantification of PAF-induced (1 $\mu$ M) PNC formation by flow cytometry $(n=7)$. (E) PAF mediated PNC formation as detected by blood smear and manual counting $(n=6)$. Data are mean \pm SD. ${ }^{*} p<0.05$, Wilcoxon matched-pairs signed rank test.

and the lack of cellular depolarization in patients with a NOX defect (46). Depolarization was followed by intracellular alkalization within minutes. The time course of the PAFinduced alkalization was in accordance with reports from bovine neutrophils (33). The change in $\mathrm{pH}_{\mathrm{i}}$ elicited by PAF was less in the study by Hidalgo et al., however, this might result from the use of different dyes and/or species differences [(33) and the results presented in this work]. In this context, it is noteworthy that shifts in neutrophil $\mathrm{pH}_{\mathrm{i}}$ are associated with other cellular functions, for example increasing chemotactic motility $(21,23$, 47). Therefore, the impact of PAF-mediated transient alkalization requires further elucidation.

In parallel, neutrophils responded to PAF stimulation with an increase in cellular size as indicated by FSC-A. The rise in cell size was confirmed by analyzing the cell volume by applying the coulter counter principle, although with less pronounced changes. In this context, previous studies with $\mathrm{C} 5 \mathrm{a}$ indicated that an increased FSC-A reflects a cellular elongation $(14,48)$ likely caused by actin polymerization (48). This possibly explains the differences between the PAF-induced changes in cell size reported by different methods. Overall, the PAF-mediated response was similar to that elicited by other chemoattractants, including the complement-derived anaphylatoxin C5a (14-16) and fMLF (18, 35, 46).

The cellular response of neutrophils induced by PAF was also investigated in the absence or presence of pharmacological inhibitors with a special interest in depolarization, intracellular $\mathrm{pH}$, and swelling. In accordance with the results obtained on neutrophil stimulation with other chemokines $(14,15,33)$, non-specific inhibition of sodium flux with amiloride and/or chloride flux with NPPB significantly reduced the intracellular alkalization and cellular swelling. Albeit amiloride also reduced depolarization, it should be noted that it also pre-depolarized unstimulated cells. Next, we investigated the role of NHE1 as an important representative ion transporter protein in stimulated granulocytes $(15,38,49)$. The pharmacological NHE1 inhibitor BIX (38, 50) also inhibited intracellular alkalization and to a lesser extent, cellular swelling, but not early depolarization. This finding of the PAF-neutrophil interaction is in accordance with previous reports for fMLF and C5a $(15,23)$, as well as the involvement of NHE1 activity during cellular polarization and migration (49). Lastly, 
A

Amiloride - sodium channels

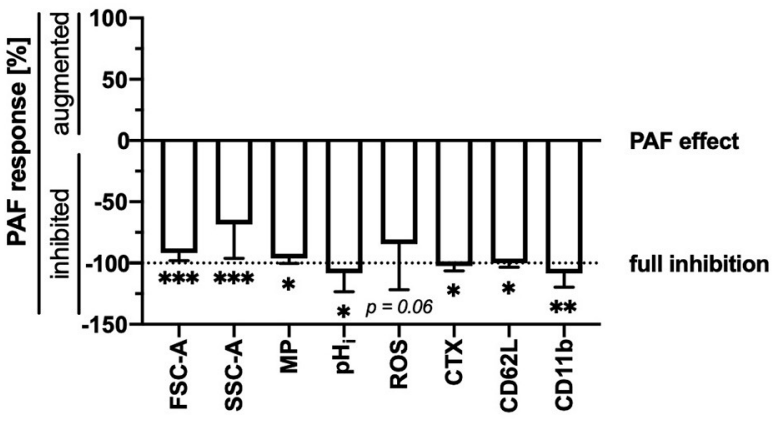

C

NPPB - chloride channels

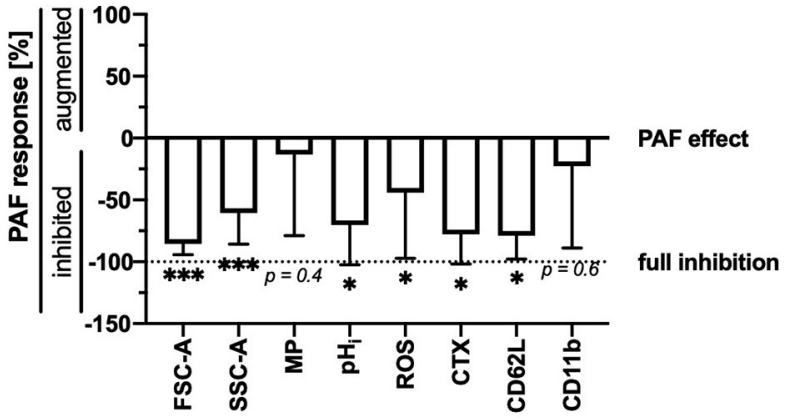

B

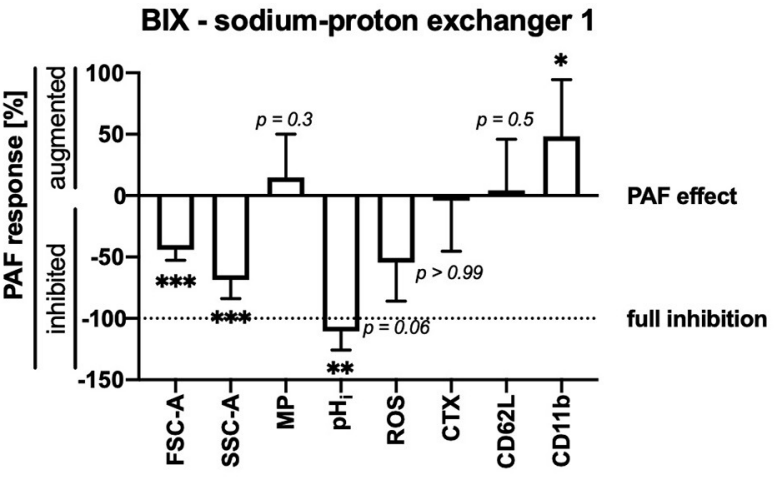

D

Ebselen - glutathione peroxidase mimic

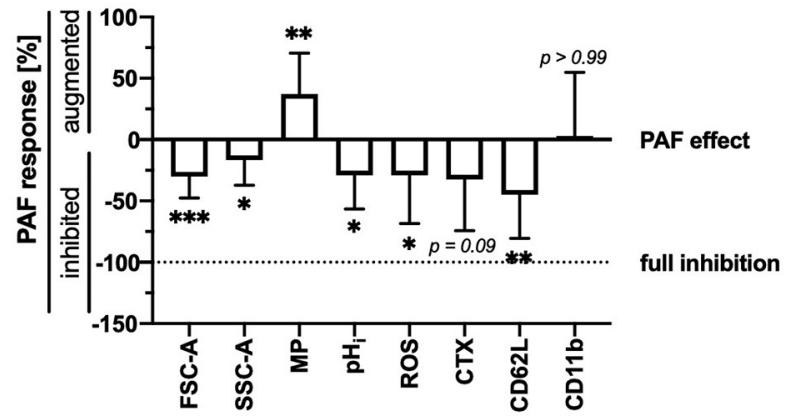

FIGURE 4 | (A) Amiloride (200 $\mu$ M), (B) BIX (5 $\mu$ M), (C) NPPB (100 $\mu$ M), and (D) ebselen (10 nM) modulated the PAF-mediated response of neutrophils. While 0\% indicates the regular response induced by $1 \mu \mathrm{M}$ PAF, $-100 \%$ indicates full inhibition of the PAF-mediated response $=$ control level. For the calculation, see Supplement 3. Data are mean \pm SD $(n=5-12) .{ }^{\star} p<0.05,{ }^{\star \star} p<0.01,{ }^{\star \star \star} p<0.001$, Wilcoxon signed-rank test.

ebselen was used as an inhibitor of NOX2 and peroxide scavenger $(40,41,51)$, which also dampened cellular swelling and alkalization but not depolarization. It is noteworthy, that exposure to either BIX or ebselen did not largely alter most cellular functions in unstimulated cells, and, therefore, might be potential targets for clinical evaluations regarding the modulation of the PAF-induced thromboinflammatory response of neutrophils.

In addition to inducing an (electro-)physiological response in neutrophils, PAF elicited chemotactic activity, CD11b upregulation and CD62L downregulation, and PNC formation which is in accordance with previous studies $(24,25,27,52)$. This "platelet satelitism" of neutrophils is also found in several pathologies, including sepsis, augmenting neutrophil activity, including extravasation, neutrophil extracellular trap formation, and bacterial killing (53-56). It is tempting to speculate that inhibition of PNC formation, possibly caused by PAF release during sepsis $(57,58)$, might be a suitable target to modulate the thromboinflammatory response. For example, the striking relevance of PNC formation has been demonstrated in a murine model of hydrochloric acid-induced acute lung injury, in which blocking PNC formation significantly ameliorated organ dysfunction (59).

\section{PAF-induced (electro-)physiological Response in the Context of Severe Inflammation}

During inflammation, neutrophils are required to migrate through various tissues and are exposed to varying levels of extracellular of extracellular proton concentrations. The $\mathrm{pH}$ of inflammatory body fluids, for example, abscesses, where neutrophils amass, is acidic (60-64). The experiment involving varying $\mathrm{pH}_{\mathrm{e}}$ indicated that even under acidic $\mathrm{pH}_{\mathrm{e}}$, neutrophils remain able to respond with a relative intracellular alkalization and cellular swelling despite a shift in their $\mathrm{pH}_{\mathrm{i}}$ in relationship to the $\mathrm{pH}_{\mathrm{e}}$. In addition, PAF-induced depolarization was increased in acidosis, potentially indicating elevated ROS generation, which has been demonstrated in a previous study (65).

Next, the effects of PAF on neutrophils were translationally investigated in two inflammatory environments. The previously described human whole blood model (36) of LPS-driven inflammation allows the investigation of blood physiology and immunity in an animal-free environment in accordance with the $3 \mathrm{R}$ principles (66). LPS exposure of whole blood altered the neutrophil phenotype as shown by CD11b and CD62L levels, confirming a sepsis-like phenotype that has been described in 


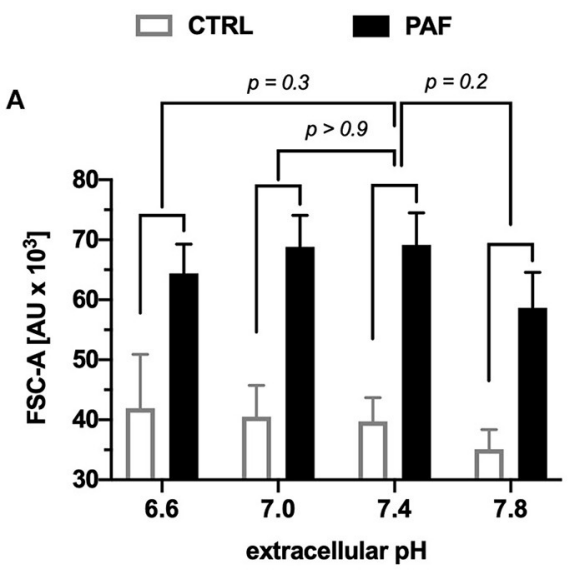

B
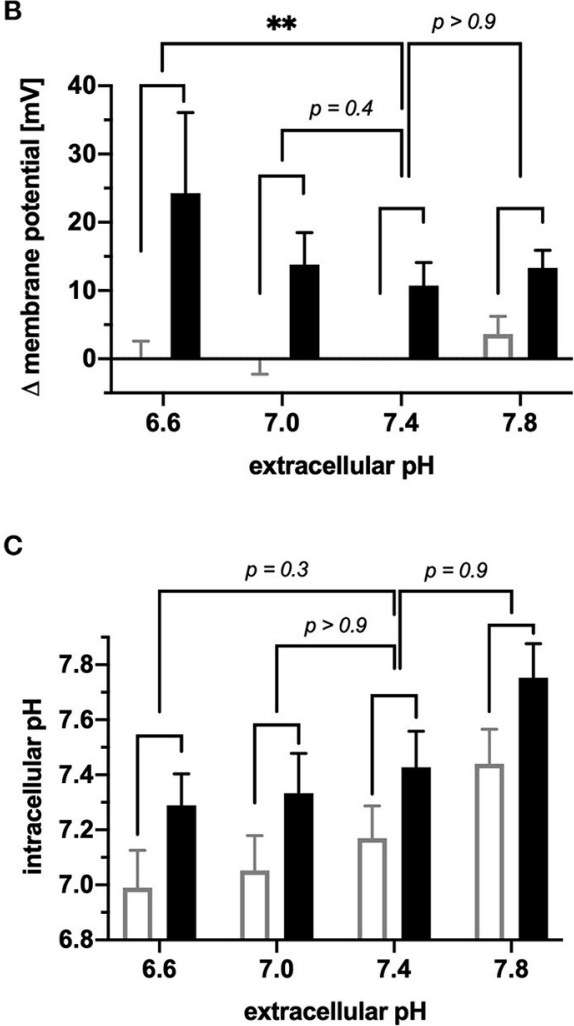

FIGURE 5 | Extracellular acidosis increased the PAF-mediated depolarization in human neutrophils in vitro. Neutrophils were incubated in buffers with different extracellular $\mathrm{pH}$ and subsequently stimulated by $1 \mu \mathrm{M}$ PAF. (A) The increase in the FSC-A induced by PAF in comparison with unstimulated neutrophils in an acidotic or alkaline environment did not significantly alter the cellular response in comparison to an extracellular $\mathrm{pH}$ of 7.4. (B) Depolarization of the membrane potential upon PAF stimulation was enhanced in an acidic environment $(0 \mathrm{mV}=\mathrm{CTRL}$ extracellular $\mathrm{pH}$ 7.4). (C) Intracellular $\mathrm{pH}$ of neutrophils stimulated with PAF (black) or PBS (CTRL, white). Data are mean $\pm \operatorname{SD}(n=6) .{ }^{* *} p<0.01$, Kruskal Wallis and Dunn's post-hoc test comparing the PAF-induced response for each extracellular $\mathrm{pH}$.

detail previously (67-71). LPS exposure did not alter the MP in comparison with unstimulated neutrophils and only augmented the PAF-induced response by a small amount. By contrast, a similar in vitro experiment comparing the depolarization of neutrophils with or without LPS exposure did report an increase in MP change, however, for fMLF (72). As observed in previous studies with neutrophils from septic humans and/or mice, exposure to LPS prompted an intracellular alkalization and swelling $(14,15,73)$. This baseline drift in unstimulated cells was accompanied by a decrease in the PAF-induced response of granulocytes, possibly indicating ceiling effects. In general, the intracellular $\mathrm{pH}$ of neutrophils can rise beyond the LPS-induced shift in resting cells and/or the measurement method is capable of detecting larger shifts, arguing against a ceiling effect. Nevertheless, it is possible that neutrophils can only generate a certain alkaline shift, being limited by the $\mathrm{pH}_{\mathrm{e}}$ that was not relevantly altered after LPS exposure in the whole blood model as reported earlier (36). LPS exposure in the whole blood model did not significantly change the sodium, potassium, or proton concentration, thus failing to explain the changes in alkalization or depolarization as reported previously (36).

Lastly, we analyzed the PAF-induced (electro-)physiological response in neutrophils before and during a well-characterized porcine model of polymicrobial sepsis (43-45). The clinical data confirmed a cardiocirculatory shock, indicating sepsis, also in corroboration with a significant hemoconcentration, suggesting a blood-organ barrier breakdown and subsequent hypovolemia. In the course of sepsis, the PAF-induced depolarization was significantly impaired, which confirmed findings in C5astimulated neutrophils after $3 \mathrm{~h}$ of porcine hemorrhagic shock (16). It is noteworthy, that there were no large shifts in extracellular ion concentrations and/or blood $\mathrm{pH}$ that could potentially explain this finding. Moreover, the PAF-mediated alkalization remained largely stable during sepsis, whereas cellular swelling was slightly increased. Also, the baseline of neutrophil $\mathrm{pH}_{\mathrm{i}}$ and FSC-A did not shift (data not shown), which is in contrast to previous results in murine and/or human sepsis $(14,15,73)$. These apparent differences in the findings within the two models might be explained by either species differences (human vs. pig), differences in the time points analyzed ( $1 \mathrm{~h}$ vs. $5.8 \mathrm{~h} \pm 3.5$ ), and/or regarding the $\mathrm{pH}_{\mathrm{i}}$ with different fluorescent probes.

\section{STRENGTHS AND LIMITATIONS}

Changes in the MP and $\mathrm{pH}_{\mathrm{i}}$ of neutrophils were measured by fluorescent dyes in vitro yielding indirect results. However, direct measurement of MP by conventional patch-clamp in neutrophils is technically challenging and potentially results in artificial activation of the cells as well as a rapid exchange of the intracellular ion concentration $(74,75)$. Additionally, the results reported in the present work, including C5a as a positive control, are in agreement with previous studies (1416). Besides not altering the neutrophil intracellular homeostasis, flow cytometry allows a high throughput of analyzed cells in comparison to the patch-clamp technique when simultaneously analyzing MP, intracellular $\mathrm{pH}$, and cellular size as indicated by FSC-A. However, patch-clamp allows a higher temporal 
A

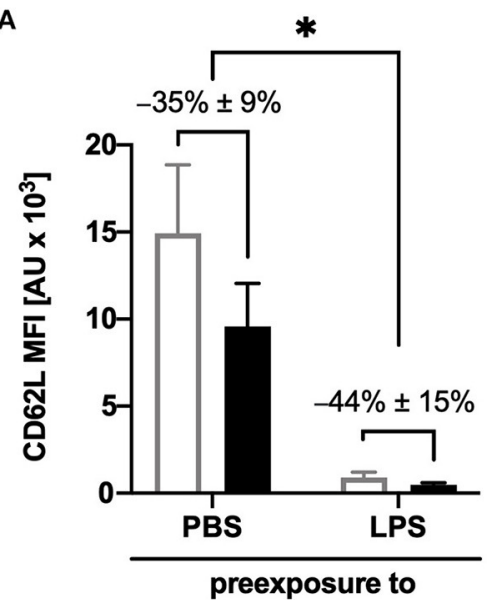

C

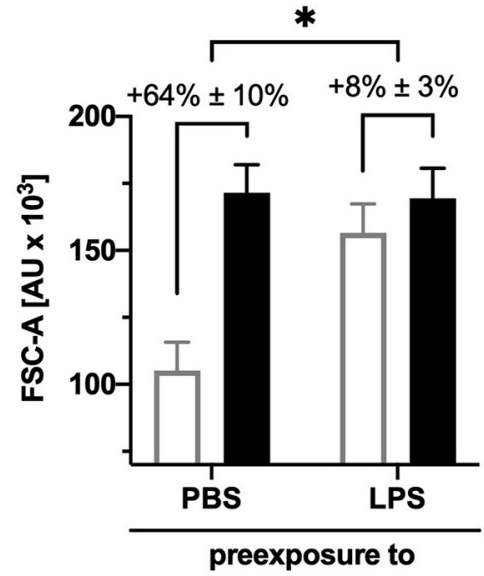

E

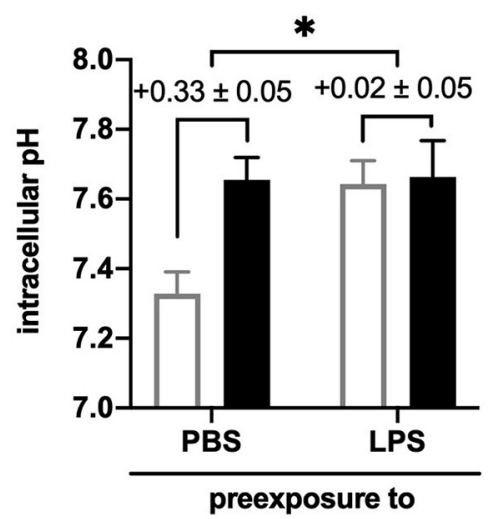

B

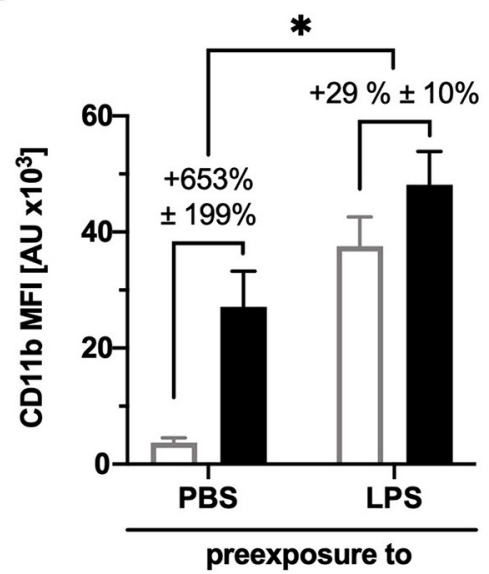

D

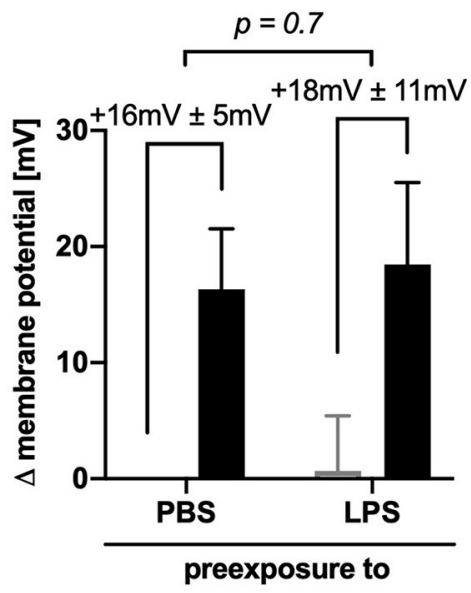

F

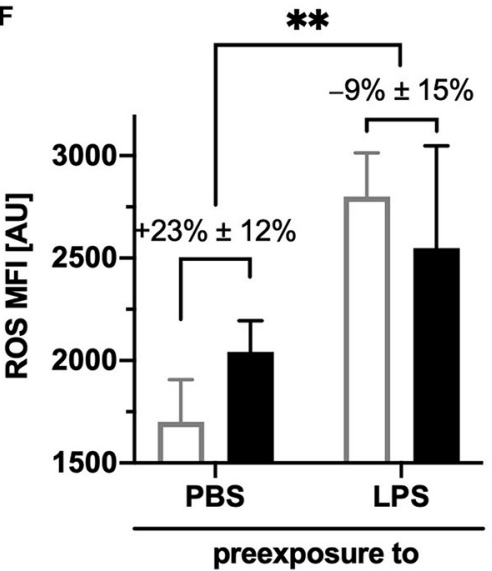

CTRL

FIGURE 6 | LPS-driven inflammation altered the PAF-induced response pattern of human neutrophils in an ex vivo whole blood model. Blood was incubated for $1 \mathrm{~h}$ with or without $100 \mathrm{ng} / \mathrm{ml}$ LPS. Subsequently, blood (A,B,F) or isolated neutrophils (C-E) were stimulated with $1 \mu$ M PAF in vitro. (A,B) Surface expression of L-selectin (CD62L, (A)) and integrin alpha M (CD11b, (B)) on neutrophils. (C) Cellular size of neutrophils as indicated by the FSC-A. (D) PAF-induced depolarization after exposure to LPS. (E) Intracellular pH of neutrophils stimulated with or without PAF. (F) PAF-mediated ROS generation. Data are mean \pm SD of the PAF-induced response $(n=6) .{ }^{*} p<0.05,{ }^{* *} p<0.01$, Wilcoxon matched-pairs signed rank test comparing the response induced by PAF of neutrophils with (LPS) or without (PBS as CTRL) stimulation in the whole blood model. MFI, mean fluorescence intensity. 
TABLE 1 | Clinical parameters of the animals before and during experimental polymicrobial sepsis.

\begin{tabular}{llccc}
\hline Parameter & Unit & Before sepsis & During sepsis & $\boldsymbol{p}$-value \\
\hline Heart rate & per min & $103 \pm 19$ & $170 \pm 32$ & $*$ \\
MAP & $\mathrm{mmHg}$ & $104 \pm 9$ & $82 \pm 9$ & $*$ \\
$\mathrm{Hb}$ & $\mathrm{g} / \mathrm{dl}$ & $8.6 \pm 0.6$ & $14.5 \pm 3.7$ & $* *$ \\
$\mathrm{pH}$ & $-\log \left(\mathrm{H}^{+}\right)$ & $7.51 \pm 0.04$ & $7.48 \pm 0.04$ & 0.08 \\
$\mathrm{Lactate}^{+}$ & $\mathrm{mM}$ & $1.4 \pm 0.5$ & $1.8 \pm 1.1$ & 0.30 \\
$\mathrm{~K}^{+}$ & $\mathrm{mM}$ & $3.0 \pm 0.2$ & $3.3 \pm 0.2$ & $*$ \\
$\mathrm{Na}^{+}$ & $\mathrm{mM}$ & $143.7 \pm 2.7$ & $143.8 \pm 2.6$ & $>0.99$ \\
$\mathrm{Ca}^{2+}$ & $\mathrm{mM}$ & $0.73 \pm 0.06$ & $0.69 \pm 0.09$ & 0.64 \\
$\mathrm{Time}^{2+}$ & $\mathrm{h}$ & - & $5.8 \pm 3.5$ & -
\end{tabular}

MAP, mean arterial pressure; $H \mathrm{~b}$, hemoglobin concentration; $\mathrm{K}^{+}$, blood potassium concentration; $\mathrm{Na}^{+}$, blood sodium concentration; $\mathrm{Ca}^{2+}$, blood calcium concentration; Time, time from initiation to decrease in MAP indicating sepsis. Data are mean $\pm S D$ $(n=9) .{ }^{*} p<0.05,{ }^{* *} p<0.01$ Wilcoxon matched-pairs signed rank test.

resolution in comparison to conventional flow cytometry. In the present work, we used continuous acquisition to partially compensate for the loss of temporal resolution. In addition, the current setup allowed the investigation of the PAFinduced cellular response in a physiologically environment at $37^{\circ} \mathrm{C}$ in the presence of $\mathrm{HCO}_{3}^{-}$, the latter being involved in neutrophil ion channel activity $(18,76)$ and thereby should be included in measuring depolarization and intracellular alkalization. It is noteworthy that the $\mathrm{HCO}_{3}^{-}$containing buffer became slightly alkalotic, thereby likely explaining the alkaline shift in unstimulated neutrophils during the measurement period.

Next, we established a clear concentration-response relationship of the cellular response to PAF. However, we mainly used a concentration of $1 \mu \mathrm{M}$ PAF (approximately $500 \mathrm{ng} / \mathrm{ml}$ ). This concentration is higher than found in blood of septic neonates $(2.3 \mathrm{ng} / \mathrm{ml})$ (57). Anyhow, one must consider that PAF acts in vivo largely as a paracrine signaling molecule and neutrophils encounter PAF via other cells in the immediate vicinity (77). Many other cell types, including platelets and endothelial cells, which are in close proximity to neutrophils (e.g., by forming PNCs), secrete PAF when stimulated, for example, with thrombin, to promote neutrophil adhesion and transmigration $(1,2,52,78)$. In accordance, a study by Mitchell et al. that investigated fluid shear stress on neutrophils and effects of PAF applied a concentration of $1 \mu \mathrm{M}$ to simulate a concentration neutrophils experience when coming into contact with endothelium (79). Further studies need to develop improved methods to quantify PAF and measure exact PAF levels locally and systemically during sepsis.

Lastly, we transferred the findings generated in vitro to the ex vivo whole blood model and the porcine sepsis model, which have several advantages and limitations. The whole blood model allowed the investigation of the PAF-induced response with or without LPS-induced inflammation in human blood in a well-defined system (36). In addition, changes of the neutrophil response to PAF were confirmed in an experimental model of polymicrobial sepsis (43-45) with a clinically relevant
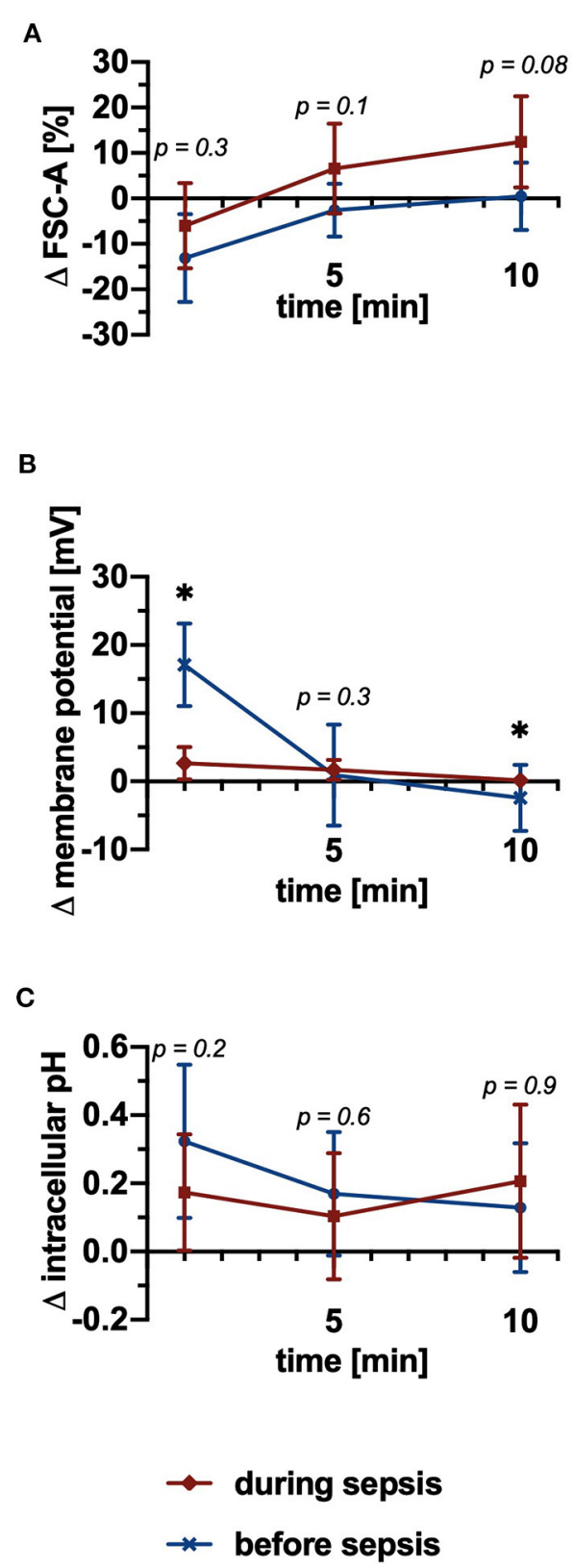

FIGURE 7 | PAF-mediated depolarization was significantly impaired and there was a trend for increased cellular swelling during experimental polymicrobial sepsis, whereas alkalization remained stable. (A) Changes of the FSC-A upon stimulation with $1 \mu \mathrm{M}$ PAF vs. unstimulated cells before (blue) and during (red) sepsis $(n=9)$. (B) PAF-induced alteration in membrane potential $(n=7)$. (C) Alterations in intracellular $\mathrm{pH}$ of PAF-exposed neutrophils $(n=9)$. Data are mean $\pm \mathrm{SD}$. ${ }^{*} p<0.05$, Wilcoxon matched-pairs signed rank test.

pathophysiological reaction. Interestingly, the results of both models varied. This might arise because of several reasons: On the one hand, there might be notable interspecies differences. On the other hand, the assay itself differed between the two models regarding the $\mathrm{pH}_{\mathrm{i}}$, because porcine neutrophils had to be analyzed with a different dye. Furthermore, there are 


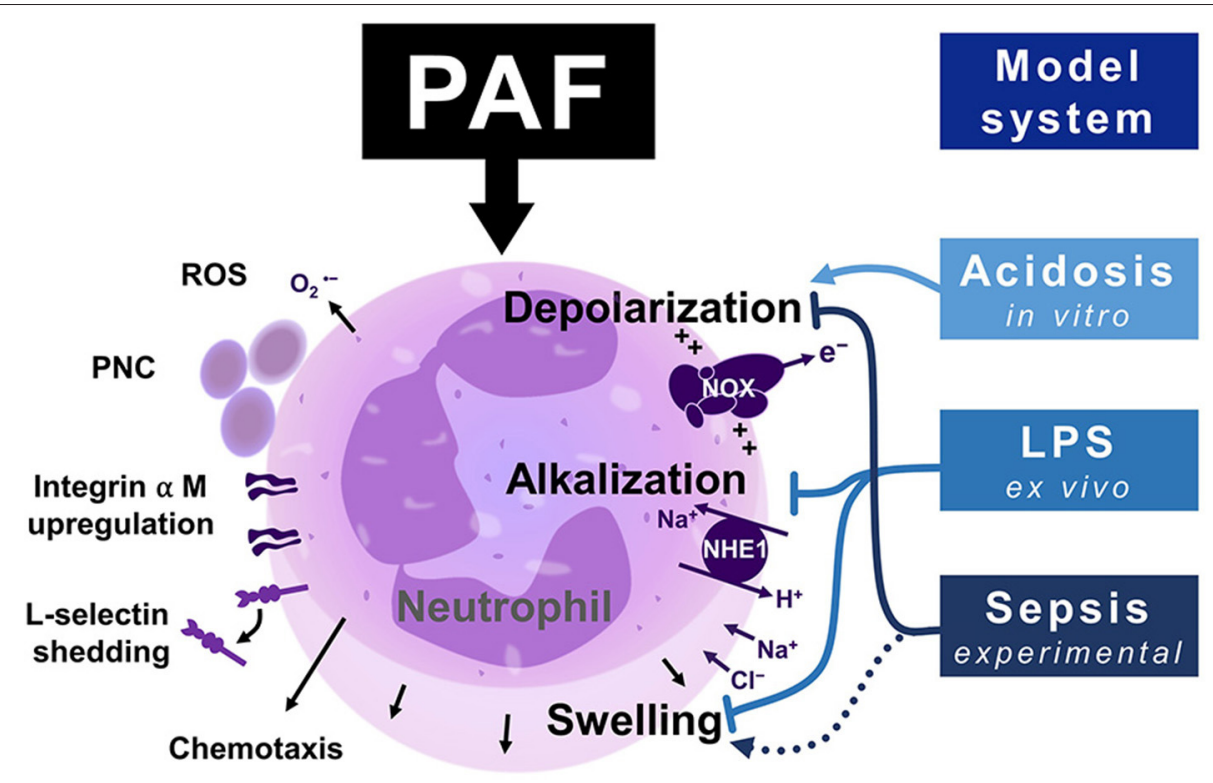

FIGURE 8 | Graphical summary of the neutrophil response upon exposure to platelet-activating factor (PAF), including depolarization, NHE1-dependent alkalization, and cellular swelling and functional thromboinflammatory activity. The (electro-)physiological response mediated by PAF is modulated in inflammatory environments. Endotoxemia increases intracellular $\mathrm{pH}$ and cell size of neutrophils while in parallel diminishing an additional change inducible by PAF. Depolarization is enhanced by extracellular acidosis, while being significantly disrupted during experimental sepsis. ROS, reactive oxygen species; PNC, platelet-neutrophil complex; NOX, NADPH oxidase; NHE1, sodium-proton exchanger 1.

different kinetics of the inflammatory response to consider: In the whole blood model of endotoxemia, there was an initial stimulation with LPS resulting in a rapid inflammatory response, while the addition of bacteria in the porcine model triggered a gradually increasing inflammation. In addition, the duration of the period analyzed and/or the inflammatory response elicited by LPS vs. fecal inoculation might explain the different results. In the whole blood model, it is difficult to analyze neutrophils in a long-term investigation, because glucose levels decline while in parallel lactate levels and acidosis increase, resulting in an unphysiological environment beyond $1 \mathrm{~h}$. These issues were circumvented and thus indicated the application of the porcine sepsis model. Moreover, the lack of the presence of the interaction of neutrophils with other organs may play an important role. Another important aspect to consider regarding the porcine sepsis model is that neutrophils were isolated at the onset of sepsis as indicated by a drop of mean arterial blood pressure but prior to severe organ dysfunction. The rationale for this was to increase the sample size, since the current experiments were embedded in an interventional trial, that started after the beginning of sepsis (reduction of animal numbers). Also, the onset of sepsis marked the initiation of a resuscitation therapy, which may have further altered the response of neutrophils and likely ameliorated the degree of the inflammatory response such as lactate acidosis. Taken together, this allowed the investigation of neutrophil dysfunction as an early hallmark of the beginning of sepsis. Further research needs to explore these findings in a non-resuscitated model of sepsis and/or during a more pronounced inflammatory response including systemic acidosis, which may reveal further changes also in $\mathrm{pH}_{\mathrm{i}}$ and FSC. Moreover, the findings need to be confirmed in patients with sepsis. Various causes of a potential neutrophil desensitization to stimulation with PAF during sepsis should be investigated, for example, a receptor downregulation of PAF, a previous stimulation by PAF in vivo, and/or a defect in PAF-signaling in sepsis. Notably, both models offer a distinct advantage investigating neutrophil pathophysiology during sepsis: Analyzing patients with sepsis does hardly allow firm assumptions regarding the onset of the infection, which was clearly defined in the model systems analyzed in this work.

\section{CONCLUSION}

Platelet-activating factor (PAF) is an important activator of neutrophils triggering depolarization, intracellular alkalization, and changes in cellular size. The PAF-induced response was demonstrated to be altered in an ex vivo model of endotoxemia and at the onset of porcine experimental sepsis, which might be an early hallmark of innate immune dysfunction during sepsis. Further studies are warranted to elucidate the association between the modulated (electro-)physiological response and cellular effector function. Additionally, translational efforts are needed to explore the therapeutic and diagnostic potential of these findings, for example, by measuring the neutrophil response at the patient's bedside and/or by targeting the involved ion channels, including NHE1, to reduce overwhelming PAFinduced neutrophil activation. 


\section{DATA AVAILABILITY STATEMENT}

The original contributions presented in the study are included in the article/Supplementary Material, further inquiries can be directed to the corresponding author.

\section{ETHICS STATEMENT}

The studies involving human volunteers were reviewed and approved by the Local Independent Ethics Committee (number $459 / 18$; 94/14) of the University of Ulm. The participants provided their written informed consent to participate in this study. The animal study was reviewed and approved by the Federal Authorities for Animal Research (\#1362, Tuebingen, Germany) as well as the Animal Care Committee of the University of Ulm.

\section{AUTHOR CONTRIBUTIONS}

$\mathrm{DM}$ and $\mathrm{MH}-\mathrm{L}$ : conceptualization and supervision. $\mathrm{SH}, \mathrm{SB}$, and DM: data curation and formal analysis. $\mathrm{SH}, \mathrm{SB}, \mathrm{PR}, \mathrm{AH}$, and DM: methodology. SH, AS, and DM: validation and visualization. SH and DM: writing-original draft. All authors contributed to the article and approved the submitted version.

\section{FUNDING}

The present work was funded by a research grant (Forum Gesundheitsstandort) of the Ministry of Science, Research and Art Baden Wuerttemberg to DACM and MHL, a start-up grant and a Gerok-Rotation (rotation as clinician scientist) to DACM by the Collaborative Research Center 1149 (project number 251293561), German Research Foundation, and a research grant (DFG Ra 396/12-1) to PR (project number 398113988), German Research Foundation. The funders had no role in the design of this study, data collection and interpretation, or decision to submit results.

\section{REFERENCES}

1. Lordan R, Tsoupras A, Zabetakis I, Demopoulos CA. Forty years since the structural elucidation of Platelet-Activating Factor (PAF): historical, current, and future research perspectives. Molecules. (2019) 24:4414. doi: 10.3390/molecules24234414

2. Gill P, Jindal NL, Jagdis A, Vadas P. Platelets in the immune response: revisiting platelet-activating factor in anaphylaxis. J Allergy Clin Immunol. (2015) 135:1424-32. doi: 10.1016/j.jaci.2015.04.019

3. Ramakrishnan AVKP, Varghese TP, Vanapalli S, Nair NK, Mingate MD. Platelet activating factor: a potential biomarker in acute coronary syndrome? Cardiovasc Ther. (2017) 35:64-70. doi: 10.1111/1755-5922.12233

4. Yost CC, Weyrich AS, Zimmerman GA. The platelet activating factor (PAF) signaling cascade in systemic inflammatory responses. Biochimie. (2010) 92:692-7. doi: 10.1016/j.biochi.2010.02.011

5. Singer M, Deutschman CS, Seymour CW, Shankar-Hari M, Annane D, Bauer $\mathrm{M}$, et al. The Third International Consensus Definitions for Sepsis and Septic Shock (Sepsis-3). JAMA. (2016) 315:801-10. doi: 10.1001/jama.2016.0287

6. Huber-Lang M, Lambris JD, Ward PA. Innate immune responses to trauma. Nat Immunol. (2018) 19:327-41. doi: 10.1038/s41590-018-0064-8

\section{ACKNOWLEDGMENTS}

The authors are indebted to Ms. Carina Kleimaier for outstanding technical assistance.

\section{SUPPLEMENTARY MATERIAL}

The Supplementary Material for this article can be found online at: https://www.frontiersin.org/articles/10.3389/fimmu. 2021.642867/full\#supplementary-material

Supplement 1 | PAF-mediated changes in the response of neutrophils were concentration-dependent. Concentration-response curves were calculated for the following parameters after stimulation with PAF $(1 \mathrm{nM}-1 \mu \mathrm{M})$ at the time point of maximal stimulation as indicated: (A) FSC-A (10 min), (B) SSC-A (10 min), (C) membrane potential (1 min), (D) intracellular pH (5 min), (E) ROS generation (10 min), (F) formation of platelet-neutrophil complexes measured by flow cytometry (15 min), (G) L-selectin (CD62L) surface expression (15 min), and (H) integrin alpha $\mathrm{M}(\mathrm{CD} 11 \mathrm{~b})$ surface expression (15 min). Data are mean $\pm \mathrm{SD}$ $(n=5-10)$.

Supplement 2 | Tabular overview of the relative PAF-induced effects on human neutrophils and gender analysis at the point of a (near-)maximal response during the first hour. FSC-A, forward scatter area; SSC-A, side scatter area; MP, membrane potential; $\mathrm{pH}_{\mathrm{i}}$, intracellular $\mathrm{pH}$; ROS, generation of reactive oxygen species; CTX, chemotaxis; CD62L, L-selectin surface expression downregulation; CD11b, integrin alpha M surface expression upregulation. Data are mean \pm standard deviation $(n=5-10) .{ }^{*} p<0.05,{ }^{* *} p<0.01,{ }^{* * *} p<0.001$, for comparing PAF vs. CTRL: MP Wilcoxon signed-rank test, for all other parameters Wilcoxon matched-pairs signed rank test. For the comparison of neutrophils from male or female donors: Mann-Whitney test.

Supplement 3 | Modulation of neutrophil parameters by pharmacological inhibitors without further stimulation. The extent of these effects was compared to the response induced by $1 \mu \mathrm{M}$ PAF. Control $=0 \%$, PAF-mediated effect $=100 \%$. Boxes outside the defined range were colored gray. For calculation see Supplement 4. FSC-A, forward scatter area; SSC-A, side scatter area; MP, membrane potential; $\mathrm{pH}_{\mathrm{i}}$, intracellular $\mathrm{pH}$; $\mathrm{ROS}$, generation of reactive oxygen species; CTX, chemotaxis; CD62L, L-selectin surface expression downregulation; CD11b, Integrin alpha M surface expression upregulation. Data are mean $(n=5-10)$.

Supplement 4 | Calculations for (A) Figure 4 and (B) the Heatmap in Supplement 3; F, mean fluorescence intensity.

7. Tang HM, Teshima DY, Lum BKB. Effects of the PAF antagonists bepafant and L-659, 989 in endotoxic and septic shock. Drug Dev Res. (1993) 29:216-21. doi: $10.1002 / \mathrm{ddr} .430290308$

8. Schuster DP, Metzler M, Opal S, Lowry S, Balk R, Abraham E, et al. Recombinant platelet-activating factor acetylhydrolase to prevent acute respiratory distress syndrome and mortality in severe sepsis: phase IIb, multicenter, randomized, placebo-controlled, clinical trial. Crit Care Med. (2003) 31:1612-9. doi: 10.1097/01.CCM.0000063267.79824.DB

9. Poeze M, Froon AHM, Ramsay G, Buurman WA, Greve JWM. Decreased organ failure in patients with severe sirs and septic shock treated with the platelet-activating factor antagonist TCV-309: a prospective, multicenter, double-blind, randomized phase II trial. Shock. (2000) 14:421-8. doi: 10.1097/00024382-200014040-00001

10. Opal S, Laterre P-F, Abraham E, Francois B, Wittebole X, Lowry S, et al. Recombinant human platelet-activating factor acetylhydrolase for treatment of severe sepsis: results of a phase III, multicenter, randomized, doubleblind, placebo-controlled, clinical trial. Crit Care Med. (2004) 32:332-41. doi: 10.1097/01.CCM.0000108867.87890.6D

11. Dhainaut JF, Tenaillon A, Hemmer M, Damas P, Le Tulzo Y, Radermacher $\mathrm{P}$, et al. Confirmatory platelet-activating factor receptor antagonist trial 
in patients with severe gram-negative bacterial sepsis: a phase III, randomized, double-blind, placebo-controlled, multicenter trial. BN 52021 Sepsis Investigator Group. Crit Care Med. (1998) 26:1963-71. doi: 10.1097/00003246-199812000-00021

12. Bosmann M, Ward PA. The inflammatory response in sepsis. Trends Immunol. (2013) 34:129-36. doi: 10.1016/j.it.2012.09.004

13. Shen X-F, Cao K, Jiang J-P, Guan W-X, Du J-F. Neutrophil dysregulation during sepsis: an overview and update. J Cell Mol Med. (2017) 21:1687-97. doi: $10.1111 / \mathrm{jcmm} .13112$

14. Denk S, Taylor RP, Wiegner R, Cook EM, Lindorfer MA, Pfeiffer K, et al. Complement C5a-induced changes in neutrophil morphology during inflammation. Scand J Immunol. (2017) 86:143-55. doi: 10.1111/sji.12580

15. Denk S, Neher MD, Messerer DAC, Wiegner R, Nilsson B, Rittirsch D, et al. Complement C5a functions as a master switch for the $\mathrm{pH}$ balance in neutrophils exerting fundamental immunometabolic effects. J Immunol. (2017) 198:4846-54. doi: 10.4049/jimmunol.1700393

16. Messerer DAC, Denk S, Föhr KJ, Halbgebauer R, Braun CK, Hönes F, et al. Complement $\mathrm{C} 5 \mathrm{a}$ alters the membrane potential of neutrophils during hemorrhagic shock. Mediat Inflamm. (2018) 2018:1-12. doi: $10.1155 / 2018 / 2052356$

17. DeCoursey TE. The intimate and controversial relationship between voltage gated proton channels and the phagocyte NADPH oxidase. Immunol Rev. (2016) 273:194-218. doi: 10.1111/imr.12437

18. Giambelluca MS, Gende OA. $\mathrm{Cl}^{-} / \mathrm{HCO}_{3}^{-}$exchange activity in fMLPstimulated human neutrophils. Biochem Biophys Res Commun. (2011) 409:567-71. doi: 10.1016/j.bbrc.2011.05.046

19. Coakley RJ, Taggart C, McElvaney NG, O’Neill SJ. Cytosolic pH and the inflammatory microenvironment modulate cell death in human neutrophils after phagocytosis. Blood. (2002) 100:3383-91. doi: 10.1182/blood.V100.9.3383

20. Grinstein S, Swallow CJ, Rotstein OD. Regulation of cytoplasmic pH in phagocytic cell function and dysfunction. Clin Biochem. (1991) 24:241-7. doi: 10.1016/0009-9120(91)80014-T

21. Simchowitz L, Cragoe EJ. Regulation of human neutrophil chemotaxis by intracellular pH. J Biol Chem. (1986) 261:6492-500.

22. Yuo A, Kitagawa S, Kasahara T, Matsushima K, Saito M, Takaku F. Stimulation and priming of human neutrophils by interleukin-8: cooperation with tumor necrosis factor and colony-stimulating factors. Blood. (1991) 78:2708-14.

23. Ritter M, Schratzberger P, Rossmann H, Wöll E, Seiler K, Seidler U, et al. Effect of inhibitors of $\mathrm{Na}^{+} / \mathrm{H}^{+}$-exchange and gastric $\mathrm{H}^{+} / \mathrm{K}^{+}$ATPase on cell volume, intracellular $\mathrm{pH}$ and migration of human polymorphonuclear leucocytes. $\mathrm{Br} J$ Pharmacol. (1998) 124:627-38. doi: 10.1038/sj.bjp.0 701864

24. Shaw JO, Pinckard RN, Ferrigni KS, McManus LM, Hanahan DJ. Activation of human neutrophils with 1-O-hexadecyl/octadecyl-2-acetyl-sn-glycerol-3phosphorylcholine (platelet activating factor). J Immunol. (1981) 127:1250-5.

25. Zoratti EM, Sedgwick JB, Vrtis RR, Busse WW. The effect of plateletactivating factor on the generation of superoxide anion in human eosinophils and neutrophils. J Allergy Clin Immunol. (1991) 88:749-58. doi: 10.1016/0091-6749(91)90182-N

26. Follin P, Johansson A, Dahlgren C. Intracellular production of reactive oxygen species in human neutrophils following activation by the soluble stimuli FMLP, dioctanoylglycerol and ionomycin. Cell Biochem Funct. (1991) 9:29-37. doi: $10.1002 / \mathrm{cbf} .290090106$

27. Berends C, Dijkhuizen B, de Monchy J, Dubois A, Gerritsen J, Kauffman H. Inhibition of PAF-induced expression of CD11b and shedding of L-selectin on human neutrophils and eosinophils by the type IV selective PDE inhibitor, rolipram. Eur Respir J. (1997) 10:1000.

28. Arnould T, Michiels $\mathrm{C}$, Remacle J. Increased PMN adherence on endothelial cells after hypoxia: involvement of PAF, CD18/CD11b, and ICAM-1. Amer J Physiol Cell Physiol. (1993) 264:C1102-C1110. doi: 10.1152/ajpcell.1993.264.5.C1102

29. Condliffe AM, Chilvers ER, Haslett C, Dransfield I. Priming differentially regulates neutrophil adhesion molecule expression/function. Immunology. (1996) 89:105-11. doi: 10.1046/j.1365-2567.1996.d01-711.x

30. Brailoiu E, Barlow CL, Ramirez SH, Abood ME, Brailoiu GC. Effects of platelet-activating factor on brain microvascular endothelial cells. Neuroscience. (2018) 377:105-13. doi: 10.1016/j.neuroscience.2018.02.039
31. Wang G-D, Wang X-Y, Hu H-Z, Fang X-C, Liu S, Gao N, et al. Plateletactivating factor in the enteric nervous system of the guinea pig small intestine. Am J Physiol Gastrointest Liver Physiol. (2006) 291:G928-37. doi: 10.1152/ajpgi.00153.2006

32. Lerner R, Lindström P, Palmblad J. Platelet activating factor and leukotriene B4 induce hyperpolarization of human endothelial cells but depolarization of neutrophils. Biochem Biophys Res Commun. (1988) 153:805-10. doi: 10.1016/s0006-291x(88)81167-7

33. Hidalgo MA, Ojeda F, Eyre P, LaBranche TP, Smith C, Hancke JL, et al. Platelet-activating factor increases $\mathrm{pH}_{(\mathrm{i})}$ in bovine neutrophils through the PI3K-ERK1/2 pathway. Br J Pharmacol. (2004) 141:311-21. doi: 10.1038/sj.bjp.0705590

34. Larrazabal CS, Carretta MD, Hidalgo MA, Burgos RA. Amiloride interferes with platelet-activating factor-induced respiratory burst and MMP-9 release in bovine neutrophils independent of $\mathrm{Na}^{+} / \mathrm{H}^{+}$exchanger 1 . Vet Immunol Immunopathol. (2017) 191:68-73. doi: 10.1016/j.vetimm.2017. 08.007

35. Hidalgo MA, Carretta MD, Teuber SE, Zárate C, Cárcamo L, Concha II, et al. fMLP-induced IL-8 release is dependent on NADPH oxidase in human neutrophils. J Immunol Res. (2015) 2015:1-14. doi: 10.1155/2015/120348

36. Messerer DAC, Vidoni L, Erber M, Stratmann AEP, Bauer JM, Braun CK, et al. Animal-free human whole blood sepsis model to study changes in innate immunity. Front Immunol. (2020) 11:571992. doi: 10.3389 /fimmu. 2020.571992

37. Elbim C, Lizard G. Flow cytometric investigation of neutrophil oxidative burst and apoptosis in physiological and pathological situations. Cytometry. (2009) 75:475-81. doi: 10.1002/cyto.a.20726

38. Huber JD, Bentzien J, Boyer SJ, Burke J, De Lombaert S, Eickmeier C, et al. Identification of a potent sodium hydrogen exchanger isoform 1 (NHE1) inhibitor with a suitable profile for chronic dosing and demonstrated cardioprotective effects in a preclinical model of myocardial infarction in the rat. J Med Chem. (2012) 55:7114-40. doi: 10.1021/jm300601d

39. Dreinhöfer J, Gögelein H, Greger R. Blocking kinetics of $\mathrm{Cl}^{-}$channels in colonic carcinoma cells (HT29) as revealed by 5-nitro-2-(3phenylpropylamino)benzoic acid (NPPB). Biochim. Biophys. Acta Biomembr. (1988) 946:135-42. doi: 10.1016/0005-2736(88)90466-X

40. Masumoto H, Kissner R, Koppenol WH, Sies H. Kinetic study of the reaction of ebselen with peroxynitrite. FEBS Lett. (1996) 398:179-82. doi: 10.1016/s0014-5793(96)01237-9

41. Smith SME, Min J, Ganesh T, Diebold B, Kawahara T, Zhu Y, et al. Ebselen and congeners inhibit NADPH oxidase 2-dependent superoxide generation by interrupting the binding of regulatory subunits. Chem Biol. (2012) 19:752-63. doi: 10.1016/j.chembiol.2012.04.015

42. Mauler M, Seyfert J, Haenel D, Seeba H, Günther J, Stallmann D, et al. Platelet-neutrophil complex formation-a detailed in vitro analysis of murine and human blood samples. J Leuk Biol. (2015) 99:781-9. doi: 10.1189/jlb.3TA0315-082R

43. Hauser B, Barth E, Bassi G, Simon F, Gröger M, Oter S, et al. Hemodynamic, metabolic, and organ function effects of pure oxygen ventilation during established fecal peritonitis-induced septic shock. Crit Care Med. (2009) 37:2465-9. doi: 10.1097/CCM.0b013e3181aee8ad

44. Nussbaum BL, Stenzel T, Merz T, Scheuerle A, McCook O, Wachter $\mathrm{U}$, et al. Hyperoxia or therapeutic hypothermia during resuscitation from non-lethal hemorrhagic shock in swine. Shock. (2017) 48:564-70. doi: 10.1097/SHK.0000000000000884

45. Nußbaum BL, Vogt J, Wachter U, McCook O, Wepler M, Matallo J, et al. Metabolic, cardiac, and renal effects of the slow hydrogen sulfide-releasing molecule GYY4137 during resuscitated septic shock in swine with pre-existing coronary artery disease. Shock. (2017) 48:175-84. doi: 10.1097/SHK.0000000000000834

46. Geiszt M, Kapus A, Német K, Farkas L, Ligeti E. Regulation of capacitative $\mathrm{Ca}^{2+}$ influx in human neutrophil granulocytes: alterations in chronic granulomatous disease. J Biol Chem. (1997) 272:26471-8. doi: $10.1074 /$ jbc. 272.42 .26471

47. Hayashi H, Aharonovitz O, Alexander RT, Touret N, Furuya W, Orlowski J, et al. $\mathrm{Na}^{+} / \mathrm{H}^{+}$exchange and $\mathrm{pH}$ regulation in the control of neutrophil chemokinesis and chemotaxis. Am J Physiol Cell Physiol. (2008) 294:C526-34. doi: 10.1152/ajpcell.00219.2007 
48. Lepidi H, Zaffran Y, Ansaldi JL, Mege JL, Capo C. Morphological polarization of human polymorphonuclear leucocytes in response to three different chemoattractants: an effector response independent of calcium rise and tyrosine kinases. J Cell Sci. (1995) 108 (Pt 4):1771-8.

49. Denker SP, Barber DL. Cell migration requires both ion translocation and cytoskeletal anchoring by the Na-H exchanger NHE1. J Cell Biol. (2002) 159:1087-96. doi: 10.1083/jcb.200208050

50. Kilić A, Huang CX, Rajapurohitam V, Madwed JB, Karmazyn M. Early and transient sodium-hydrogen exchanger isoform 1 inhibition attenuates subsequent cardiac hypertrophy and heart failure following coronary artery ligation. J Pharmacol Exp Ther. (2014) 351:492-9. doi: 10.1124/jpet.114.217091

51. Bedard K, Krause K-H. The NOX family of ROS-generating NADPH oxidases: physiology and pathophysiology. Physiol Rev. (2007) 87:245-313. doi: 10.1152/physrev.00044.2005

52. Sanderson HM, Fox SC, Robbins RA, Losche W, Spangenberg P, Heptinstall S. Role of GPIIb-IIIa in platelet-monocyte and plateletneutrophil conjugate formation in whole blood. Platelets. (1998) 9:245-50. doi: 10.1080/09537109876780

53. Bauer HM. In-vitro platelet-neutrophil adherence. Am J Clin Pathol. (1975) 63:824-7. doi: 10.1093/ajcp/63.6.824

54. Page C, Pitchford S. Neutrophil and platelet complexes and their relevance to neutrophil recruitment and activation. Int Immunopharmacol. (2013) 17:1176-84. doi: 10.1016/j.intimp.2013.06.004

55. Zarbock A, Polanowska-Grabowska RK, Ley K. Platelet-neutrophilinteractions: linking hemostasis and inflammation. Blood Rev. (2007) 21:99-111. doi: 10.1016/j.blre.2006.06.001

56. Zucoloto AZ, Jenne CN. Platelet-neutrophil interplay: insights into Neutrophil Extracellular Trap (NET)-driven coagulation in infection. Front Cardiovasc Med. (2019) 6:85. doi: 10.3389/fcvm.2019.00085

57. Kültürsay N, Kantar M, Akisü M, Hüseyinov A, Coker I. Platelet-activating factor concentrations in healthy and septic neonates. Eur J Pediatr. (1999) 158:740-1. doi: 10.1007/s004310051191

58. Mariano F. Production of platelet-activating factor in patients with sepsisassociated acute renal failure. Nephrol Dial Transplant. (1999) 14:1150-7. doi: $10.1093 / \mathrm{ndt} / 14.5 .1150$

59. Zarbock A, Singbartl K, Ley K. Complete reversal of acid-induced acute lung injury by blocking of platelet-neutrophil aggregation. J Clin Invest. (2006) 116:3211-9. doi: 10.1172/JCI29499

60. Hays RC, Mandell GL. $\mathrm{pO}_{2}, \mathrm{pH}$, and redox potential of experimental abscesses. Exp Biol Med. (1974) 147:29-30. doi: 10.3181/00379727-147-38275

61. Bryant RE, Rashad AL, Mazza JA, Hammond D. $\beta$-Lactamase activity in human pus. J Infect Dis. (1980) 142:594-601. doi: 10.1093/infdis/142.4.594

62. Simmen HP, Blaser J. Analysis of $\mathrm{pH}$ and $\mathrm{pO}_{2}$ in abscesses, peritoneal fluid, and drainage fluid in the presence or absence of bacterial infection during and after abdominal surgery. Am J Surg. (1993) 166:24-7. doi: 10.1016/s0002-9610(05)80576-8

63. Simmen H-P, Battaglia $\mathrm{H}$, Giovanoli P, Blaser J. Analysis of $\mathrm{pH}, \mathrm{pO}_{2}$ and $\mathrm{pCO}_{2}$ in drainage fluid allows for rapid detection of infectious complications during the follow-up period after abdominal surgery. Infection. (1994) 22:386-9. doi: 10.1007/BF01715494

64. Wagner C, Sauermann R, Joukhadar C. Principles of antibiotic penetration into abscess fluid. Pharmacology. (2006) 78:1-10. doi: 10.1159/000094668

65. Riemann A, Schneider B, Ihling A, Nowak M, Sauvant C, Thews $\mathrm{O}$, et al. Acidic environment leads to ROS-induced MAPK signaling in cancer cells. PLoS ONE. (2011) 6:e22445. doi: 10.1371/journal.pone. 0022445

66. Russell WMS, Burch RL. The Principles of Humane Experimental Technique. Wheathampstead: Universities Federation for Animal Welfare (1992).

67. Pillay J, Kamp VM, van Hoffen E, Visser T, Tak T, Lammers J-W, et al. A subset of neutrophils in human systemic inflammation inhibits $\mathrm{T}$ cell responses through Mac-1. J Clin Invest. (2012) 122:327-36. doi: 10.1172/JCI5 7990

68. van Wessem KJP, Heeres M, Leliefeld PHC, Koenderman L, Leenen LPH. Lipopolysaccharide and hemorrhagic shock cause systemic inflammation by different mechanisms. J Trauma Acute Care Surg. (2013) 74:37-44. doi: 10.1097/TA.0b013e3182789489

69. Demaret J, Venet F, Friggeri A, Cazalis M-A, Plassais J, Jallades L, et al. Marked alterations of neutrophil functions during sepsisinduced immunosuppression. J Leukoc Biol. (2015) 98:1081-90. doi: 10.1189/jlb.4A0415-168RR

70. Groeneveld KM, Koenderman L, Warren BL, Jol S, Leenen LPH, Hietbrink F. Early decreased neutrophil responsiveness is related to late onset sepsis in multitrauma patients: an international cohort study. PLOS ONE. (2017) 12:e0180145. doi: 10.1371/journal.pone.0180145

71. Maini AA, George MJ, Motwani MP, Day RM, Gilroy DW, O’Brien AJ. A comparison of human neutrophils acquired from four experimental models of inflammation. PLoS ONE. (2016) 11:e0165502. doi: 10.1371/journal.pone.0165502

72. Forehand JR, Pabst MJ, Phillips WA, Johnston RB. Lipopolysaccharide priming of human neutrophils for an enhanced respiratory burst. Role of intracellular free calcium. J Clin Invest. (1989) 83:74-83. doi: 10.1172/JCI113887

73. Nicholson GC, Tennant RC, Carpenter DC, Sarau HM, Kon OM, Barnes PJ, et al. A novel flow cytometric assay of human whole blood neutrophil and monocyte CD11b levels: upregulation by chemokines is related to receptor expression, comparison with neutrophil shape change, and effects of a chemokine receptor (CXCR2) antagonist. Pulmon Pharmacol Ther. (2007) 20:52-9. doi: 10.1016/j.pupt.2005.11.009

74. Jankowski A, Grinstein S. A noninvasive fluorimetric procedure for measurement of membrane potential quantification of the NADPH oxidaseinduced depolarization in activated neutrophils. J Biol Chem. (1999) 274:26098-104. doi: 10.1074/jbc.274.37.26098

75. DeCoursey TE, Cherny VV, Zhou W, Thomas LL. Simultaneous activation of NADPH oxidase-related proton and electron currents in human neutrophils. Proc Natl Acad Sci USA. (2000) 97:6885-9. doi: 10.1073/pnas.100047297

76. Simchowitz L. Chemotactic factor-induced activation of $\mathrm{Na}^{+} / \mathrm{H}^{+}$ exchange in human neutrophils. II. Intracellular $\mathrm{pH}$ changes. J Biol Chem. (1985) 260:13248-55.

77. Bussolino F, Camussi G. Platelet-activating factor produced by endothelial cells. Eur J Biochem. (1995) 229:327-37. doi: 10.1111/j.1432-1033.1995.0327k.x

78. Prescott SM, Zimmerman GA, McIntyre TM. Human endothelial cells in culture produce platelet-activating factor (1-alkyl-2-acetyl-sn-glycero-3phosphocholine) when stimulated with thrombin. Proc Natl Acad Sci USA. (1984) 81:3534-8. doi: 10.1073/pnas.81.11.3534

79. Mitchell MJ, Lin KS, King MR. Fluid shear stress increases neutrophil activation via platelet-activating factor. Biophys J. (2014) 106:2243-53. doi: 10.1016/j.bpj.2014.04.001

Conflict of Interest: The authors declare that the research was conducted in the absence of any commercial or financial relationships that could be construed as a potential conflict of interest.

Copyright (c) 2021 Hug, Bernhard, Stratmann, Erber, Wohlgemuth, Knapp, Bauer, Vidoni, Fauler, Föhr, Radermacher, Hoffmann, Huber-Lang and Messerer. This is an open-access article distributed under the terms of the Creative Commons Attribution License (CC BY). The use, distribution or reproduction in other forums is permitted, provided the original author(s) and the copyright owner(s) are credited and that the original publication in this journal is cited, in accordance with accepted academic practice. No use, distribution or reproduction is permitted which does not comply with these terms. 